\title{
Economic Guide for Identifying and Evaluating Industry Research Investments
}

A Focus on Applied Manufacturing Research

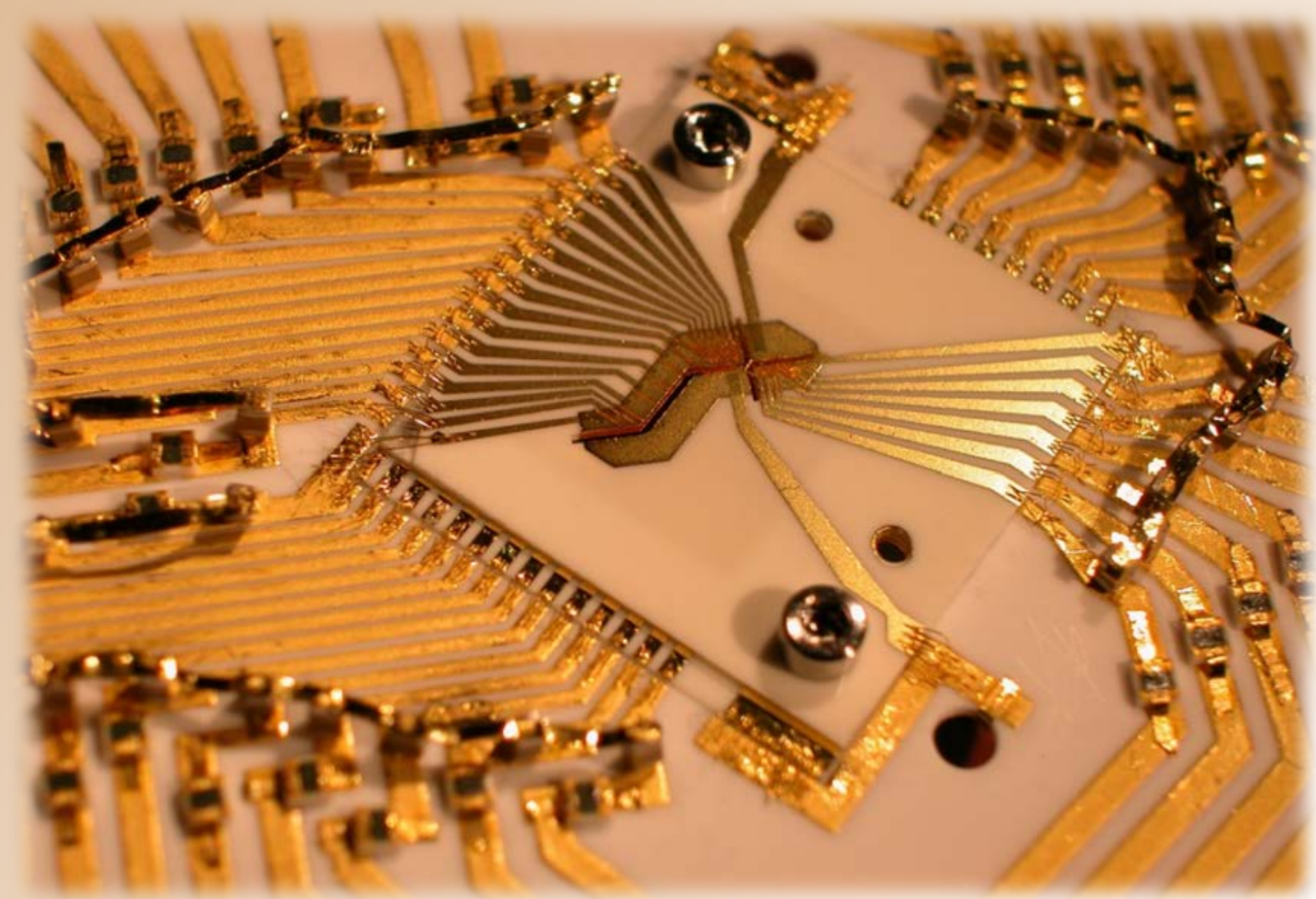

This guide aids change agents, such as research and trade organizations, in selecting potential research and development investments in the manufacturing industry.

Douglas S. Thomas Anand Kandaswamy

This publication is available free of charge from: https://doi.org/10.6028/NIST.AMS.200-8

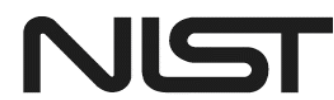

National Institute of Standards and Technology U.S. Department of Commerce 


\section{NIST Advanced Manufacturing Series 200-8}

\section{Economic Guide for Identifying and Evaluating Industry Research Investments \\ A Focus on Applied Manufacturing Research}

Douglas S. Thomas

Anand Kandaswamy

Applied Economics Office

Engineering Laboratory

This publication is available free of charge from:

https://doi.org/10.6028/NIST.AMS.200-8

December 2019

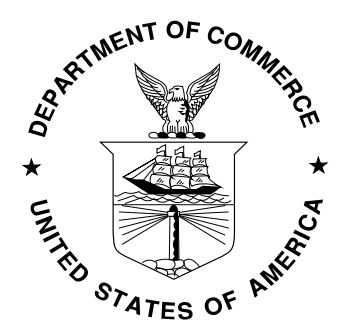

U.S. Department of Commerce Wilbur L. Ross, Jr., Secretary

National Institute of Standards and Technology Walter Copan, NIST Director and Undersecretary of Commerce for Standards and Technology 
Certain commercial entities, equipment, or materials may be identified in this document in order to describe an experimental procedure or concept adequately. Such identification is not intended to imply recommendation or endorsement by the National Institute of Standards and Technology, nor is it intended to imply that the entities, materials, or equipment are necessarily the best available for the purpose.

National Institute of Standards and Technology Advanced Manufacturing Series 200-8

Natl. Inst. Stand. Technol. Adv. Man. Ser. 200-8, 65 pages (December 2019)

This publication is available free of charge from:

https://doi.org/10.6028/NIST.AMS.200-8 


\section{Executive Summary}

This guide was assembled to aid change agents, such as research and trade organizations, in evaluating potential research and development investments in the manufacturing industry. It includes an overview of the primary methods used for evaluating investments in manufacturing technologies along with tailoring methods for change agent investments. The process presented in this guide has 5 steps with each step having a section of the guide dedicated to it:

Step 1. Identify potential industry cost research areas: This step has a number of issues and methods for identifying potential cost research areas, including the following:

- The selection of potential research projects should not be left to chance, but rather be oriented toward potentially fruitful areas.

- Search for potential change agent investments in high cost areas of manufacturing where there is a high level of value added nationally and high potential for return on investment.

- Identify projects in those industries that serve as a high cost supply chain point to many industries as opposed to just one.

- Consider the costs/benefits of using a product (i.e., quality of the product) when identifying potential research areas.

- In addition to considering costs, look for projects in industries that have a high environmental impact or high level of safety incidents to find high return projects.

- Identify research projects that span across impact/cost categories, across commodities, and across time.

- Identify high return projects that private industry struggles to address by finding projects that address market failures.

Step 2. Measure Industry Costs using a Problem-Based Approach: This step has 4 primary issues that are mentioned:

- An individual familiar with economic and/or cost data should be engaged in measuring industry costs.

- As many cost categories as possible should be measured, covering, if possible, the entirety of relevant economic activity (i.e., all manufacturing activities).

- Use a problem/cost-based focus (described in the text) to examine the costs that manufacturers face.

- When possible, measure the cost components rather than an aggregated total cost.

Step 3. Identify Potential Methods/Projects for Reducing Identified Costs/Impacts: Three tactics for successful project/method identification are discussed:

- One should not simply adopt the first good idea that comes about nor should a brainstorm session be cut short.

- Generate ideas while holding back critiquing them until a later time (i.e., deferring judgment).

- The presence of experts in multiple fields of research can provide perspectives that might not have been revealed otherwise. 
Step 4. Evaluate Costs/Benefits using a Solution-Based Approach: Several methods and issues are discussed in regards to evaluating costs/benefits:

- There are four major challenges that arise in this step: 1) absence of data, 2) uncertainty, 3) diffusion rate of a new technology/process, and 4) mixed units of measurement.

- Change agents can use accepted methods of investment analysis, such as internal rate of return and net present value, to evaluate potential projects.

- Approximate reasonable boundaries for missing data.

- Graph the range of cost and benefits for each project.

- Use Monte Carlo analysis, a probabilistic sensitivity analysis, to address uncertainty.

- An economic assessment of a research investment in applied manufacturing will, in many cases, need to consider the rate of adoption and diffusion of a new technology.

- Use the Analytical Hierarchy Process to create relative weights when there are costs/benefits measured in different units.

Step 5. Select projects based on economics, capabilities, and other factors: The last step includes a number of items to consider when selecting projects for investment:

- A benefit of using measurable criteria, such as those in an economic assessment, is that it can put downward pressure on costs and upward pressure on benefits.

- Without an economic assessment, there is little incentive to conserve resources below the budget constraint.

- If it is necessary to use intuition, it should be on the evaluation of specific factors of an investment.

- Don’t put all your eggs in one basket.

o As one invests more and more into a project, it can drag down the return on investment (i.e., net present value, benefit cost ratio, and internal rate of return) through diminishing returns.

o No matter how confident we are about the future of a project, there is some risk of it failing.

- Although an economic analysis might tend to be deterministic, there are, generally, items left to the discretion of management that might alter an investment decision.

- It is important to remember that an economic analysis of a project is a model and forecast of future economic events and, like all models and forecasts, there are limitations to the insights that are drawn from it.

- Some managers are tempted to intensify internal competition within an organization using economic assessments. While evidence suggests that competition between companies often spurs productivity, internal competition can damage productivity and can serve as a barrier to adopting economic analyses. 


\section{Acknowledgements}

The authors wish to thank all those who contributed so many excellent ideas and suggestions for this report. Special appreciation is extended to Joshua Kneifel and David Butry of the Engineering Laboratory's Applied Economics Office for their thorough reviews and insights. The authors also wish to thank Michael Brundage, of the Information Modeling and Testing Group and Nicos Martys, of the Materials and Structural Systems Division for their review. 


\section{Contents}

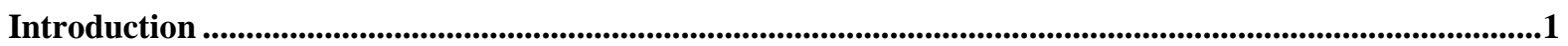

Step 1. Identify Potential Industry Cost Research Areas ...............................................................

Step 2. Measure Industry Costs using a Problem-Based Approach ..........................................................9

Step 3. Identify Potential Methods/Projects for Reducing Identified Costs/Impacts...........................12

Step 4. Evaluate Costs/Benefits using a Solution-Based Approach .........................................................14

Step 5. Select projects based on economics, capabilities, and other factors.............................................25

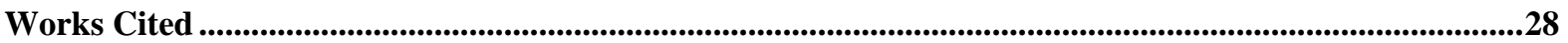

Appendix A: Supplemental Explanation of Economic Methods ..........................................................................31

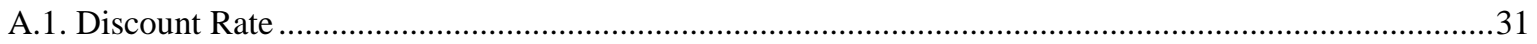

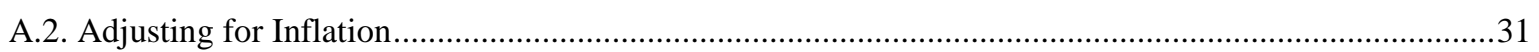

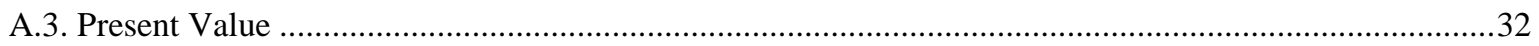

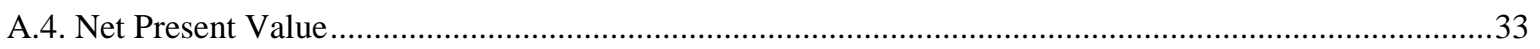

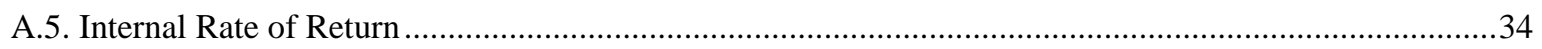

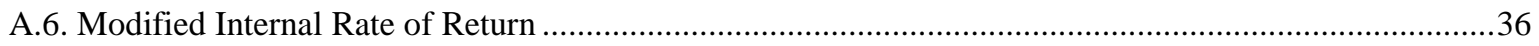

A.7. Payback Period and Discounted Payback Period ...............................................................................36

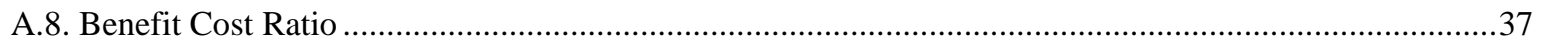

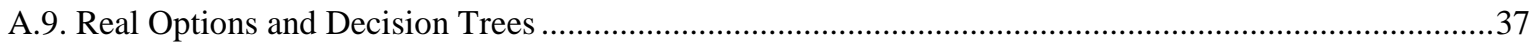

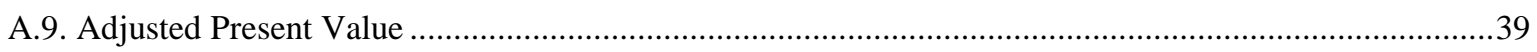

Appendix B: Supplemental Information for Dealing with Uncertainty ...........................................................41

B.1. Sensitivity Analysis with Monte Carlo Techniques ...............................................................................41

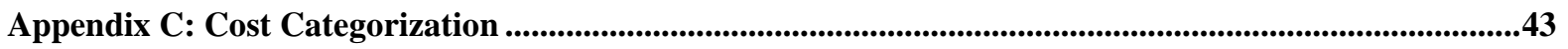

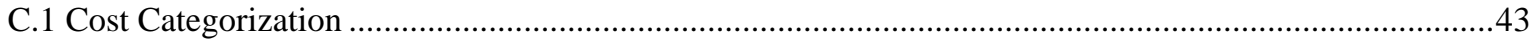

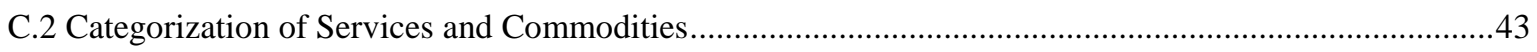

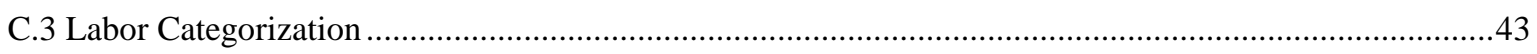

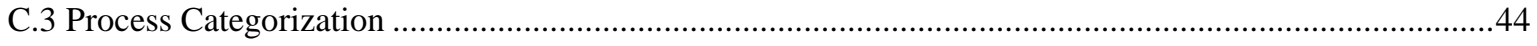

Appendix D: The Analytical Hierarchy Process ...........................................................................................................52 


\section{Figures}

Figure 1: Steps for Evaluating Change Agent Investments in Manufacturing Research and

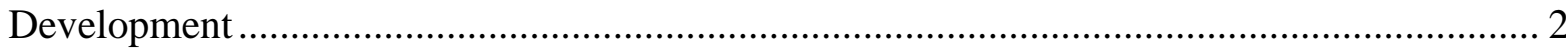
Figure 2: Cost and Benefit Combinations for Potential Research and Development Projects . 3 Figure 3: Line Graph of the Cumulative Percent of cost by Percentile of Industry/Occupation Cost (Assembly-Centric Products) 4

Figure 4: Automobile Manufacturing Supply Chain Entities Above the $70^{\text {th }}$ Percentile for Labor Hours, Environmental Impact, and Value Added ............................................... 6

Figure 5: Venn Diagram of Cost/Impact Category Intersections ....................................... 8

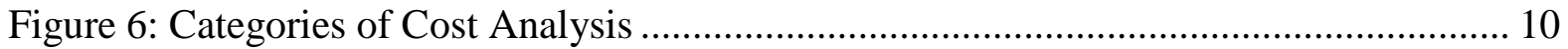

Figure 7: Potential Economic Impact of Change Agent Research and Development in Manufacturing................................................................................................... 14

Figure 8: Graphing Costs and Benefits: Examining Benefit-Cost Ratio (BCR) .................. 20

Figure 9: Graphing Costs and Benefits: Examining Net Present Value .............................. 20

Figure 10: Illustration of Internal Rate of Return ....................................................... 21

Figure 11: Logistic S-Curve Model of Diffusion ............................................................ 22

Figure A. 1: Example of a Decision Tree using a 7 \% Discount Rate.................................. 39

Figure B. 1: Frequency Graph of the Total Cost for Ball Bearing Example using a Triangular

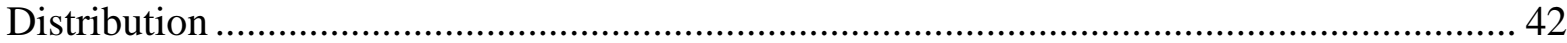

Figure B. 2: Frequency Graph of the Total Cost for Ball Bearing Example using a Uniform

Distribution ........................................................................................................ 42

Figure D. 1: Illustration of AHP Criteria and Sub-Criteria ........................................... 57

\section{Tables}

Table 1: Automobile Manufacturing Supply Chain Entities Above the $80^{\text {th }}$ Percentile for Labor Hours, Environmental Impact, and Value Added .................................................... 7 Table 2: Survey Response to "How Frequently does your Firm use the Following Techniques when Deciding which Projects or Acquisitions to Pursue" ................................................ 15

Table 3: Application of Methods for Investment Analysis................................................ 17

Table 4: Examples of Manufacturing Industry Investment Decisions.................................. 17

Table 5: Limitations and Considerations of Methods for Investment Analysis .................... 18

Table C. 1: North American Industry Classification System, Two Digit Codes ................... 44

Table C. 2: Standard Occupational Classification System, Two Digit Codes....................... 45

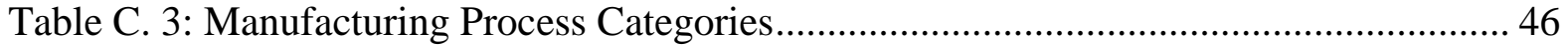

Table C. 4: Selection of Manufacturing Process Classifications ........................................ 47

Table C. 5: Manufacturing Process Classification (Based on Todd et al. 1994) .................... 49

Table D. 1: AHP Numerical Scale ................................................................................. 53

Table D. 2: Example of AHP Pairwise Comparisons for Solar Panels ................................ 54

Table D. 3: Example of AHP Comparison of Sub-Criteria for Solar Panels......................... 55

Table D. 4: AHP Example of Geometric Mean, Weight, and Consistency Measure for Solar

Panel Sub-Criteria ..................................................................................................... 55

Table D. 5: Example of AHP Pairwise Comparison Matrix for Solar Panels ....................... 55

Table D. 6: Example of Geometric Mean, Weight, and Consistency Measure for Solar Panels

56

Table D. 7: Example of AHP Weighting for Solar Panels ............................................... 56 


\section{Introduction}

There are numerous research and development investment opportunities for change agents, such as research and trade organizations, to increase efficiency and productivity in the manufacturing industry. Unfortunately, there are scarce and limited resources to invest; therefore, to have the largest impact possible, change agents must identify those investments that have the highest returns. This process requires assembling data on the research costs along with identifying the benefits of change agent expenditures on manufacturing industry research. The benefits, however, span across categories with multiple attributes, including reduced production costs, quality improvement of the finished product, reduction in the environmental impact, reduced flow time, and reduced injuries. Additionally, there is limited data on these benefits.

There are many methods that have been developed and used for economic decision making, including net present value, internal rate of return, and payback period. These methods each have their strengths and weaknesses. Some methods of evaluation allow for using multiple metrics, such as those used to measure environmental impacts and safety. Currently, there is limited guidance available for evaluating change agent investments in manufacturing.

This guide was assembled to aid change agents in evaluating potential research and development investments in the manufacturing industry. It includes an overview of the primary methods used for evaluating investments in manufacturing technologies along with tailoring methods for change agent investments. It is not a comprehensive review of investment decision making, but rather selects those methods that can be readily applied by non-experts.

The process presented in this guide has 5 steps, as outlined in Figure 1. The first step is to identify potential research areas. For instance, energy consumption for lighting, machinery maintenance, or transportation costs. The second step is to measure the costs/impacts of each research area using a problem-based approach, which is explained in the following sections. The third step is to identify potential projects for reducing costs. This might include advancing energy efficiency in lighting, developing standards for machinery maintenance, or developing analytics for transportation logistics. The fourth step is to conduct an economic assessment of each potential project using a solution-based approach (discussed later in the text) and the fifth step is to select a project.

Measuring the benefits of change agent research faces the challenge of multiple attributes (e.g., quality and cost) and limited data availability. The benefits of change agent research in manufacturing includes, but is not limited to, five categories:

1. Reduced production costs

2. Reduced flow time 
3. Improved quality of finished product

4. Environmental impact reduction

5. Improved safety

Some of these categories can be measured in dollars while others can be converted or translated into dollars using some assumptions. An alternative to translating benefits to dollars is to use a method called the Analytical Hierarchy Process to evaluate relative weights for comparing different benefit categories.

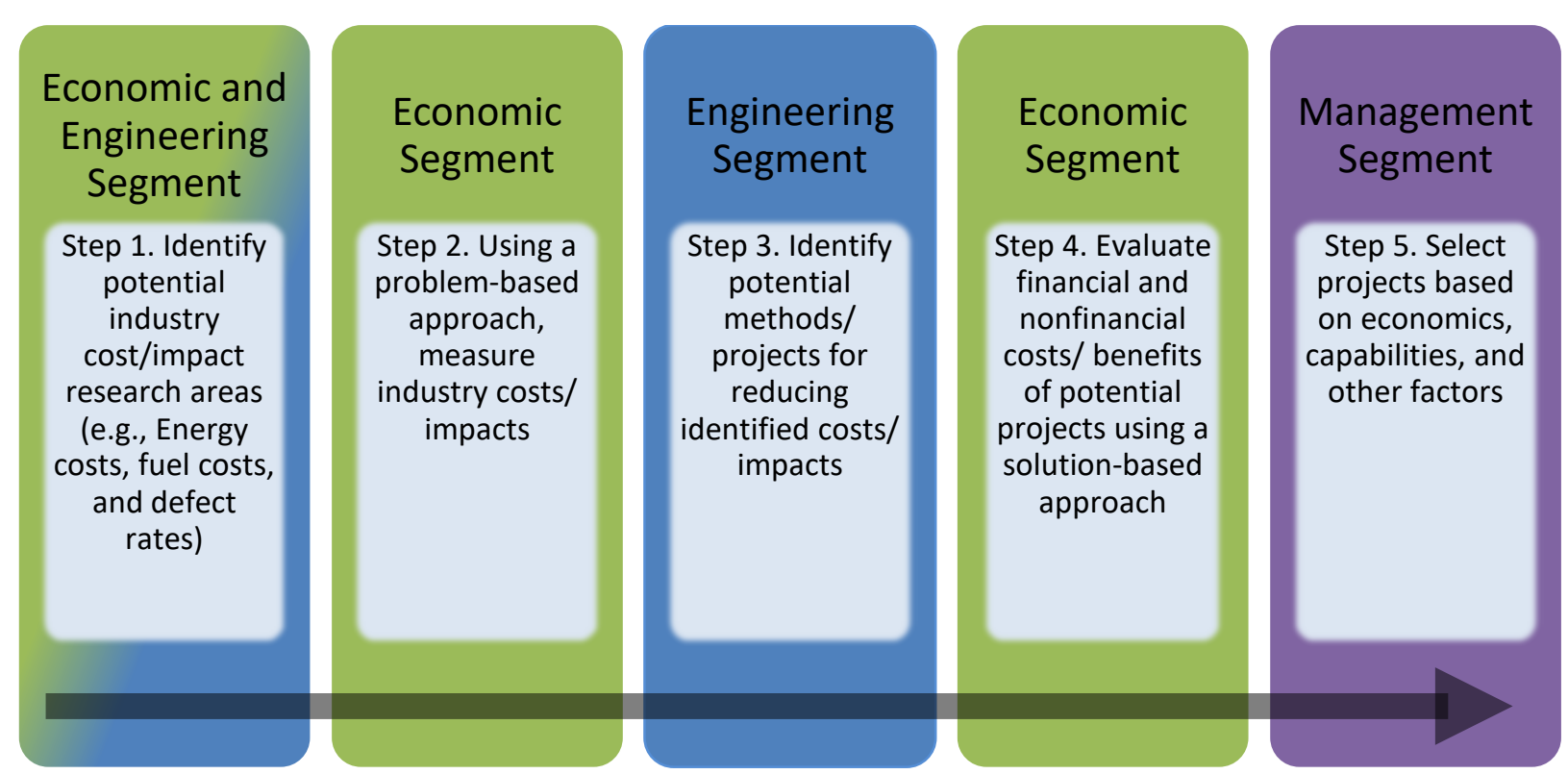

Note: Green represents primarily economic activities, blue represents primarily engineering activities, and purple represents primarily management activities. Note that these are the general types of activities and not a description of the people engaged in the activity.

Figure 1: Steps for Evaluating Change Agent Investments in Manufacturing Research and Development 


\section{Step 1. Identify Potential Industry Cost Research Areas}

The first step in identifying high return research investments that change agents can make in manufacturing, is to identify broader cost research areas that will have a high potential for having substantial return on investment. It is not technically feasible to identify all possible change agent investments in manufacturing; however, one can increase the probability of identifying a selection of investments that have a high return when compared to all the known and unknown potential investments. To illustrate, suppose that Figure 2 plots the costs and benefits for all the potential projects, known and unknown, for change agent investment in manufacturing. To have the largest impact possible, a change agent would want to identify as many projects as possible that are in the top left of this figure where there are low costs and high benefits. If projects are randomly selected or, worse, biased toward those in the lower right of the figure, it will result in a lower return on investment than might otherwise have been achieved. Moreover, the selection of potential research projects should not be left to chance, but rather be oriented toward potentially fruitful areas.

There are some approaches that increase the probability of identifying projects that have lower costs and higher benefits. A frequently invoked axiom posits that roughly $80 \%$ of a problem is due to $20 \%$ of the cause, a phenomenon referred to as the Pareto principle. ${ }^{1}$

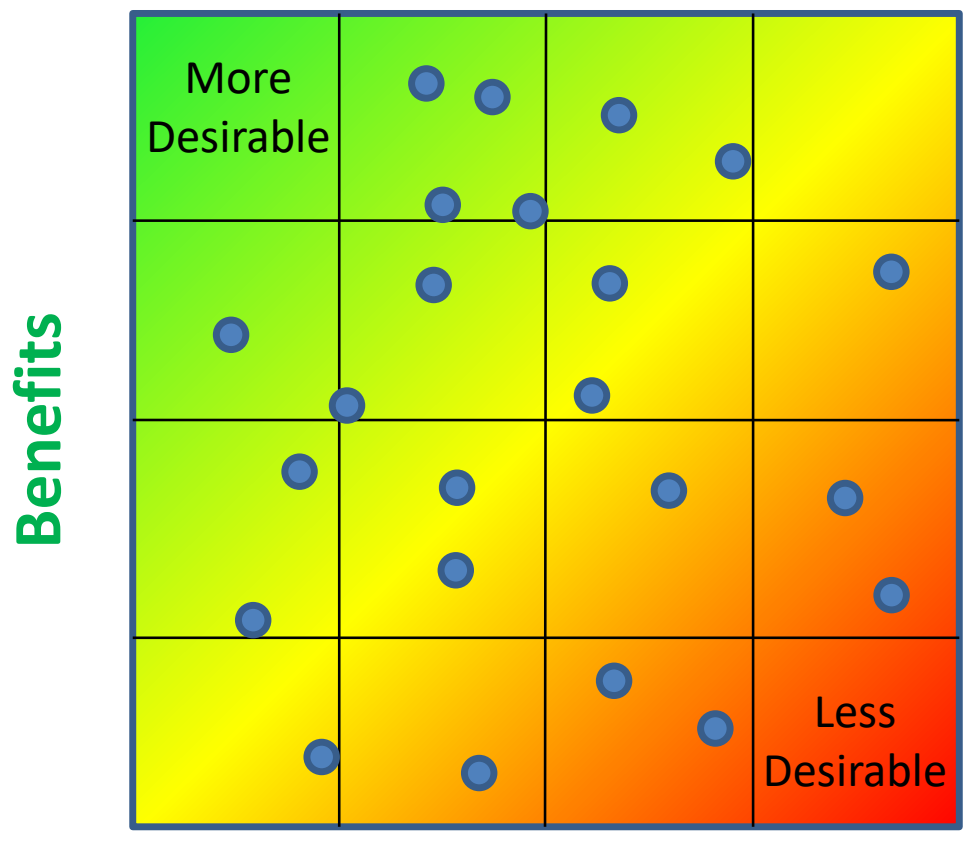

\section{Costs}

Figure 2: Cost and Benefit Combinations for Potential Research and Development Projects

\footnotetext{
${ }^{1}$ Hopp, Wallace J. \& Mark L. Spearman. (2008) Factory Physics. Third Edition. Long Grove, IL: Waveland Press. (pp. 674).
} 
Thomas and Kandaswamy (2017) show that this phenomenon is consistent with manufacturing supply chain costs and manufacturing labor costs as seen in Figure 3. ${ }^{2}$ This figure shows that, for assembly-centric products (i.e., discrete manufacturing), the total cost (categorized by labor categories and/or industry categories such as electricity, fuel, metal, and plastics) of producing a finished product are concentrated toward a small number of categories. Thomas (2018) also shows that an increase in research and development for the top quartile industries (i.e., the largest $25 \%$ of industries by value added) has a 4.9 times larger average impact on value added than the same increase on the bottom quartile. ${ }^{3}$ He also shows that a decrease in flow time for the top quartile, measured in value added, has an impact 8.5 times greater than that of the lowest quartile. The implication is that research and development expenditures have a larger return on investment for larger industries/costs as does work-in-process flow time. Moreover, change agents can search for potential investments in high cost areas of manufacturing where there is a high level of value added nationally and high potential for return on investment. This does not mean that projects should necessarily be exclusive to these categories, but they are more likely to have abundant high return opportunities.

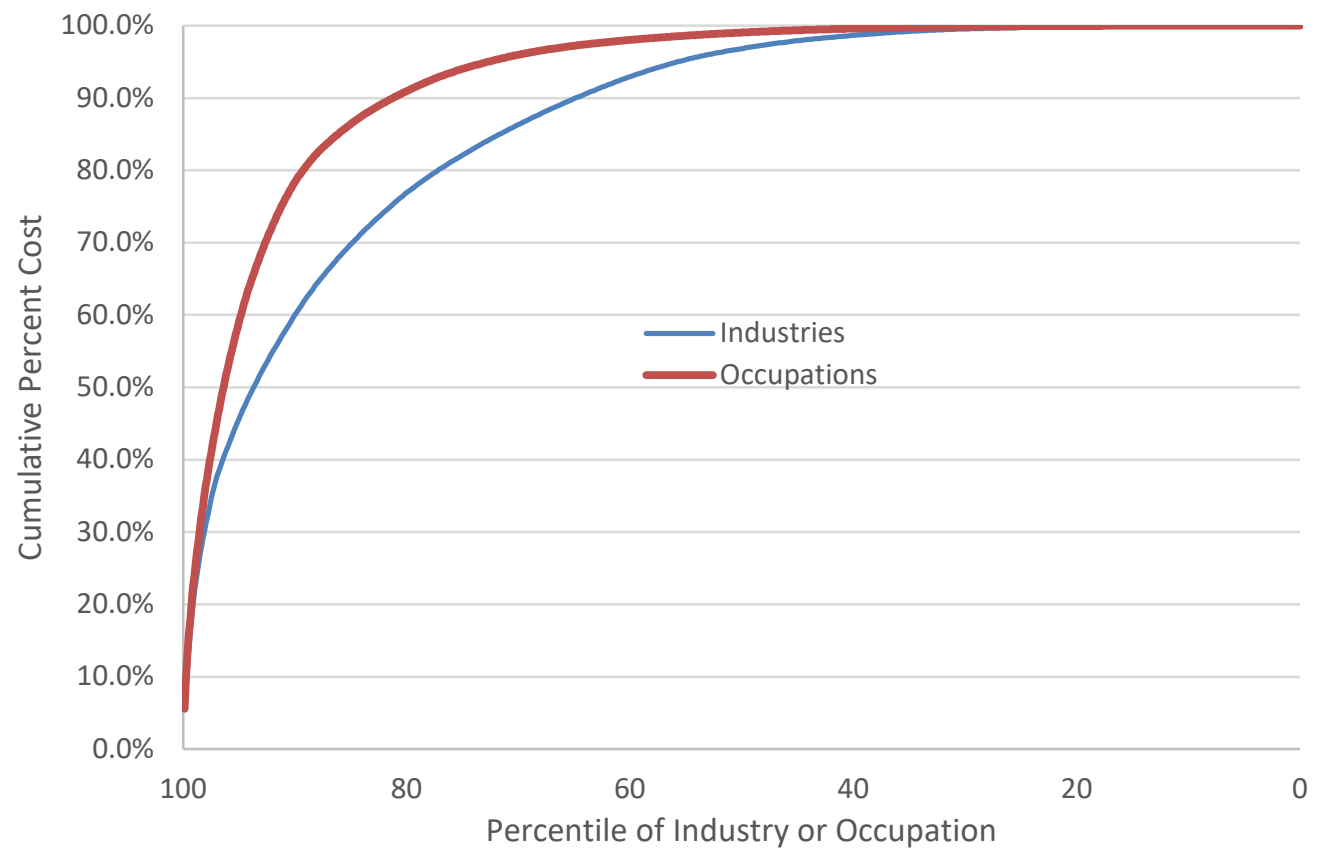

Figure 3: Line Graph of the Cumulative Percent of cost by Percentile of Industry/Occupation Cost (Assembly-Centric Products)

\footnotetext{
${ }^{2}$ Thomas, Douglas and Anand Kandaswamy. (2017) "Identifying High Resource Consumption Areas of Assembly-Centric Manufacturing in the United States.” Journal of Technology Transfer. 1-48. https://link.springer.com/article/10.1007/s10961-017-9577-9

${ }^{3}$ Thomas, Douglas. "The Effect of Flow Time on Productivity and Production.” Unpublished article. 2018.
} 
Another method for increasing the probability of identifying high return on investment projects is to identify projects in those industries that serve as a high cost supply chain point to many industries as opposed to just one. Reducing these types of costs have a high potential for having a large impact. To identify such industries, one can use inputoutput data, which maps out inter-industry purchases, along with eigenvector centrality, which measures the influence of nodes in a network. Projects that affect many industries have the potential for gaining support from numerous stakeholders.

A reduction in manufacturing costs tend to result in an increase in profits and compensation while reducing the purchase price, impacting the owners, employees, and consumers. However, it is important to remember that production costs are only a portion of the costs relevant to manufactured products. Consumers purchase and utilize products to achieve some end use purpose. Automobiles, for example, transport people and goods and cell phones are used for communication. The resources consumed in using manufactured goods along with the life expectancy can have significant impacts for the consumer and society. For instance, Thomas shows that each year in the US approximately $\$ 388$ billion are spent annually on new vehicles, but an additional $\$ 4.4$ trillion in resources are consumed annually for maintaining and using vehicles. This includes the upkeep, fuel, and a value of the time spent operating the vehicle. Moreover, change agents might consider the costs/benefits of using a product (i.e., quality of the product) when identifying potential research areas.

In addition to dollar costs, there are at least two other factors to consider, safety and environmental impact, which affects employees and the general population. Change agent research in manufacturing often aims to reduce injuries and environmental impact and many of the issues that were previously discussed transfer to these factors. In addition to looking at dollar costs, change agents can look for projects in industries that have a high environmental impact or high level of safety incidents to find high return projects. Additionally, these two factors are also important in the use of manufactured products. Projects can aim to increase product safety or decrease the environmental impact of the use and disposal of a product.

Thomas et al.(2017) have shown that some cost areas span across multiple cost/impact categories. ${ }^{4}$ For instance, there are a number of cost areas for automobile manufacturing that are above the $80^{\text {th }}$ percentile in value added (i.e., cost), environmental impact, and labor hours, as seen in Figure 4 and Table 1. Thomas (2019) also has shown that there are cost/impact areas that span across time (i.e., they are persistent) and commodities, as illustrated in Figure 5. ${ }^{5}$ Change agents can identify research projects that span across impact/cost categories, across commodities, and across time. These projects are likely to

\footnotetext{
4 Thomas, Douglas, Anand Kandaswamy, and Joshua Kneifel. "Identifying High Resource Consumption Supply Chain Points: A Case Study in Automobile Production.” 25th International Input-Output Conference. 2017. https://www.iioa.org/conferences/25th/papers.html

${ }^{5}$ Thomas, Douglas. "Reliability of using Periodic IO Data to Identify High Return Investments in Efficiency and Environmental Sustainability: An Examination of US Manufactured Tech Products.” 27 ${ }^{\text {th }}$ International Input-Output Association Conference. 20019. https://www.iioa.org/conferences/27th/papers/files/3747_20190128020_Thomas.pdf
} 
have significant impacts on society, as they have substantial effects on items that have continuously had a high cost/impact and affect multiple stakeholders.

The last issue to note in regards to identifying potential projects, is that the primary purpose of change agent investments is to address what is commonly referred to in economics as market failures. Private firms, driven by competition, frequently achieve advances in efficiency/productivity on their own accord; however, there are often barriers to advancement that surpass the ability or incentive of any single firm (i.e., a market failure). Additionally, competition, lack of communication, and other factors can prevent the collaborative efforts necessary to overcome such barriers. It is in these types of situations that change agent research efforts are often necessary for advancing industry efficiency and productivity. These market failures are instances where the market outcome or allocation of goods and services is not efficient. Thus, change agents can identify high return projects that private industry struggles to address by finding projects that address market failures.

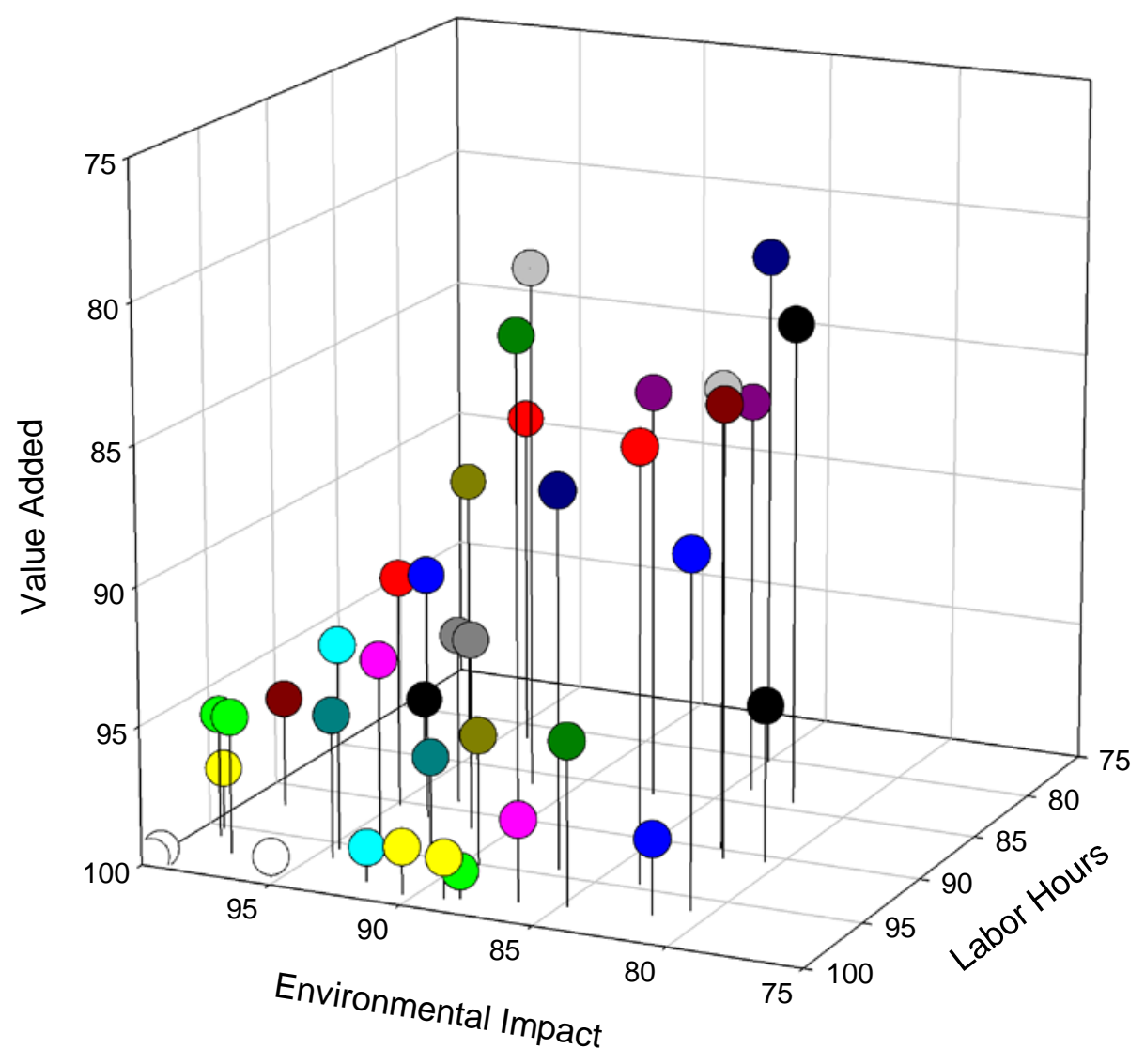

Note: Table 1 is the Key to the colors in this figure

Figure 4: Automobile Manufacturing Supply Chain Entities Above the $70^{\text {th }}$ Percentile for Labor Hours, Environmental Impact, and Value Added 
Table 1: Automobile Manufacturing Supply Chain Entities Above the $80^{\text {th }}$ Percentile for Labor Hours, Environmental Impact, and Value Added

\begin{tabular}{|c|c|c|c|c|c|c|}
\hline \multirow{2}{*}{\multicolumn{2}{|c|}{ Color }} & \multirow[b]{2}{*}{ Code } & \multirow[b]{2}{*}{ NAICS Description } & \multicolumn{3}{|c|}{ Percentile } \\
\hline & & & & Labor & $\begin{array}{l}\text { Envir. } \\
\text { Impact }\end{array}$ & $\begin{array}{l}\text { Value } \\
\text { Added }\end{array}$ \\
\hline$* *$ & & $2121,2211,2212$ & Electricity and Natural Gas & 100 & 100 & 100 \\
\hline ** & & 336111 & Automobile manufacturing & 100 & 100 & 100 \\
\hline ** & & 420000 & Wholesale trade & 99 & 95 & 99 \\
\hline ** & & 331110 & Iron and steel mills and ferroalloy manufacturing & 95 & 99 & 98 \\
\hline ** & & 327200 & Glass and glass product manufacturing & 96 & 99 & 96 \\
\hline ** & & 484000 & Truck transportation & 98 & 98 & 95 \\
\hline * & & 336390 & Other motor vehicle parts manufacturing & 98 & 92 & 99 \\
\hline * & & 550000 & Management of companies and enterprises & 99 & 90 & 98 \\
\hline * & & 316000 & Leather and allied product manufacturing & 92 & 99 & 96 \\
\hline * & & 326190 & Other plastics product manufacturing & 97 & 94 & 95 \\
\hline * & & 331520 & Nonferrous metal foundries & 96 & 95 & 93 \\
\hline * & & 333618 & Other engine equipment manufacturing & 94 & 92 & 97 \\
\hline$*$ & & 331510 & Ferrous metal foundries & 96 & 93 & 93 \\
\hline$*$ & & 482000 & Rail transportation & 90 & 95 & 92 \\
\hline$*$ & & 326210 & Tire manufacturing & 92 & 91 & 93 \\
\hline$*$ & & 331200 & Steel product manufacturing from purchased steel & 91 & 93 & 91 \\
\hline & & 336350 & Motor vehicle transmission and power train parts manufacturing & 99 & 89 & 99 \\
\hline & & 336310 & Motor vehicle gasoline engine and engine parts manufacturing & 99 & 88 & 99 \\
\hline & & 336370 & Motor vehicle metal stamping & 98 & 86 & 97 \\
\hline & & 332720 & Turned product and screw, nut, and bolt manufacturing & 95 & 89 & 95 \\
\hline & & 211000 & Oil and gas extraction & 84 & 97 & 98 \\
\hline & & 332710 & Machine shops & 98 & 85 & 94 \\
\hline & & 336360 & Motor vehicle seating and interior trim manufacturing & 97 & 82 & 97 \\
\hline & & $33441 \mathrm{~A}$ & Other electronic component manufacturing & 89 & 93 & 94 \\
\hline & & 325211 & Plastics material and resin manufacturing & 81 & 97 & 91 \\
\hline & & 332800 & Coating, engraving, heat treating and allied activities & 94 & 87 & 86 \\
\hline & & 334413 & Semiconductor and related device manufacturing & 91 & 81 & 94 \\
\hline & & 561700 & Services to buildings and dwellings & 96 & 81 & 87 \\
\hline & & 212100 & Coal mining & 82 & 94 & 88 \\
\hline & & 336211 & Motor vehicle body manufacturing & 95 & 83 & 84 \\
\hline & & 322210 & Paperboard container manufacturing & 89 & 91 & 83 \\
\hline & & 339990 & All other miscellaneous manufacturing & 86 & 92 & 81 \\
\hline & & 326110 & Plastics packaging materials/unlaminated film/sheet manufacturing & 85 & 87 & 85 \\
\hline & & 332310 & Plate work and fabricated structural product manufacturing & 91 & 82 & 84 \\
\hline & & 33211B & Crown and closure manufacturing and metal stamping & 90 & 83 & 83 \\
\hline & & 33299B & Other fabricated metal manufacturing & 83 & 84 & 86 \\
\hline & & 326290 & Other rubber product manufacturing & 84 & 82 & 83 \\
\hline & & 325510 & Paint and coating manufacturing & 80 & 85 & 81 \\
\hline
\end{tabular}

This step (i.e., step 1) involves only identifying cost areas. A good place to begin this process is looking at standard cost categories, such as the North American Industry Classification System (NAICS), Standard Occupational Classification System (SOC), and manufacturing process categories. Appendix C provides a list of these categories. 
This step (i.e., Step 1) has a number of tactics that were discussed for identifying potential cost research areas, including the following:

- The selection of potential research projects should not be left to chance, but rather be oriented toward potentially fruitful areas.

- Search for potential change agent investments in high cost areas of manufacturing where there is a high level of value added nationally and high potential for return on investment.

- Identify projects in those industries that serve as a high cost supply chain point to many industries as opposed to just one.

- Consider the costs/benefits of using a product (i.e., quality of the product) when identifying potential research areas.

- In addition to considering costs, look for projects in industries that have a high environmental impact or high level of safety incidents to find high return projects.

- Identify research projects that span across impact/cost categories, across commodities, and across time.

- Identify high return projects that private industry struggles to address by finding projects that address market failures.

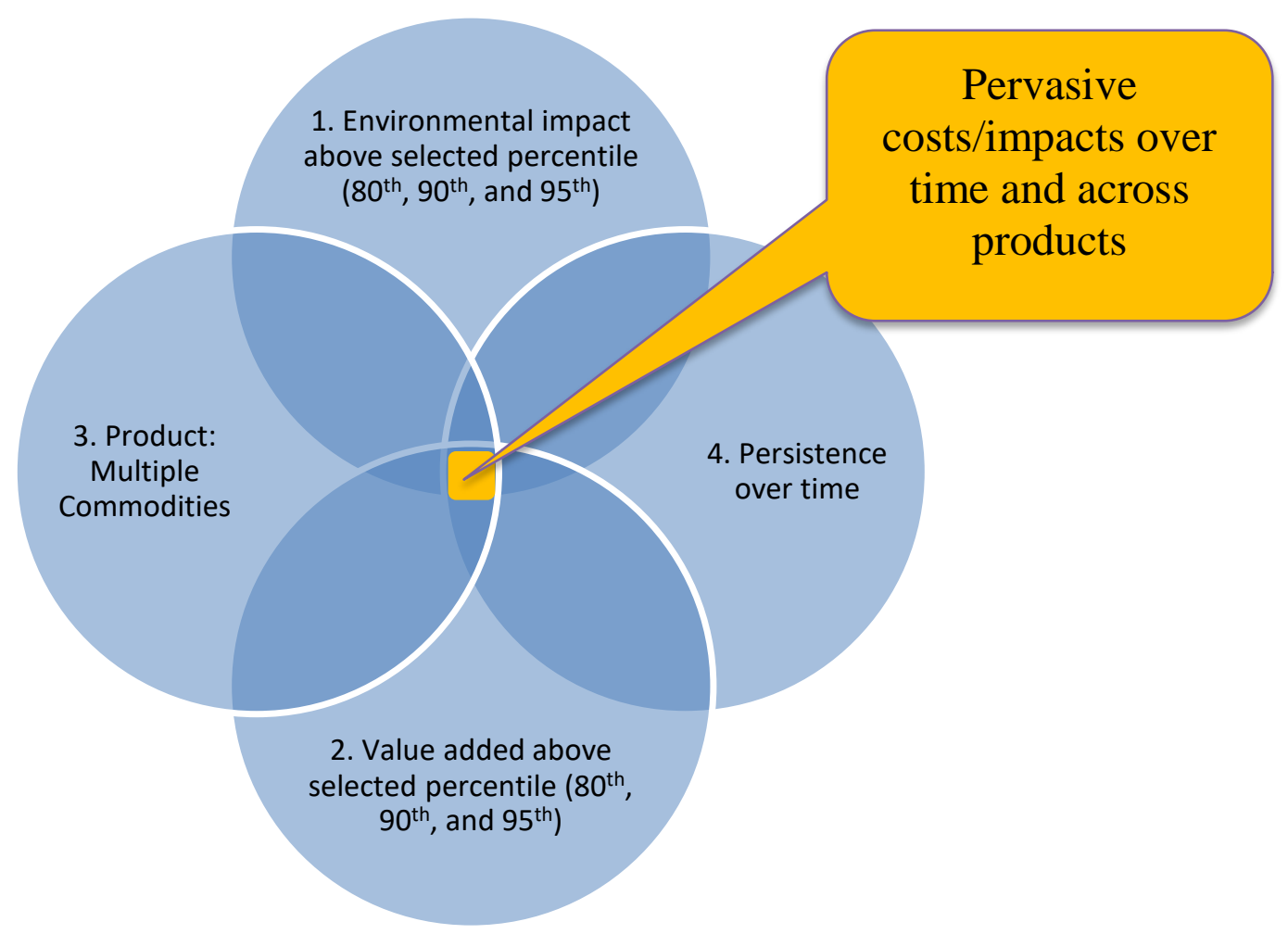

Figure 5: Venn Diagram of Cost/Impact Category Intersections 


\section{Step 2. Measure Industry Costs using a Problem-Based Approach}

Step 2 involves measuring cost areas identified in Step 1. Some caution should be exercised in this step, as missteps are common. Generally, an individual familiar with economic and/or cost data should be engaged in this step. Like many fields, there are caveats that are easy to overlook. There have been, for example, instances of double counting some types of economic activity. Some metrics, inherently, have problems related to double counting. These types of caveats are best identified by individuals familiar with measuring costs and industry activity.

As many cost categories as possible should be measured, covering, if possible, the entirety of relevant economic activity (i.e., all manufacturing activities). One of the principal goals here is to understand what the largest costs of manufacturing include so that those research areas of potentially high return can be identified. For business owners or in one's household expenditures, this approach is a more intuitive process. For example, if one wants to significantly reduce their monthly household expenditures, one would, generally, start with examining their largest costs (e.g., mortgage and utilities) rather than their smallest ones. Large costs are examined because small efficiency gains in these costs have higher returns than that in small costs. Identifying high-cost/highreturn areas is critical in research, as there is significant investment of time and resources in a research project.

Examining the costs of potential research areas often has either a solution-based focus or a problem/cost-based focus. The difference is somewhat subtle or blurred but it is perceptible, and it impacts the application of the data along with the revealed insights. As illustrated in , a solution-based focus in manufacturing examines the reduced cost that might result from a particular improvement, investment, or technology. For instance, examining the impact of adopting energy efficient lighting. An alternative to a solutionbased focus is a problem/cost-based focus where costs are categorized by more natural classifications and avoids specifying a solution. For instance, the total expenditures on energy for lighting. There are many solutions to reducing lighting costs (e.g., energy efficient lighting, turning off some lights, or inserting skylights) and a solution-based approach could be used to examine each, but each of these solutions addresses a particular cost characterized in a problem-based approach. This step uses a problem/costbased focus to examine the costs that manufacturers face. The benefit of such a focus is that it does not assume a solution and it provides information that measures the magnitude of the problem to be solved (e.g., the costs associated with inadequate modeling data, maintenance, or energy).

Another aspect of a cost analysis is the aggregation of costs. At least two challenges arise with high levels of aggregation. The first is the accuracy of the analysis. If data for an analysis is gathered at too aggregated of a level, there is the risk of a loss in accuracy, particularly in a solution-based approach, as this approach often cuts across cost categories. To illustrate, consider a survey that asks someone to estimate the hours per year they spend driving their car compared to one that asks each component of their drive time (e.g., number of hours per day they spend driving to and from work). An aggregated 
question such as one on the total hours per year they spend driving is difficult to answer, as they must consider all at once the different places that they drive. Someone is much more likely to estimate with accuracy the amount of time they spend driving to work and other individual components of their total driving. The second challenge with high levels of aggregation is that it limits the insights of being able to identify solutions or efficiency improvements. The more aspects of the costs that are measured, the more possible solutions that might be identified and compared. Unfortunately, the more components there are, the higher the cost in data collection and analysis, which could make a study infeasible. To the extent possible, change agents can measure the cost components rather than the aggregated cost to increase accuracy and usefulness of data.

When working through step 2, there is a need to strive for component level costs. This will lay the foundation for identifying potential projects in step 3. A research organization will, likely, need to build and maintain this knowledge/data over time, as measuring one cost area could require data collection. This collection of knowledge is necessary for this step and will be indispensable in measuring the costs/benefits of potential projects in step 4.

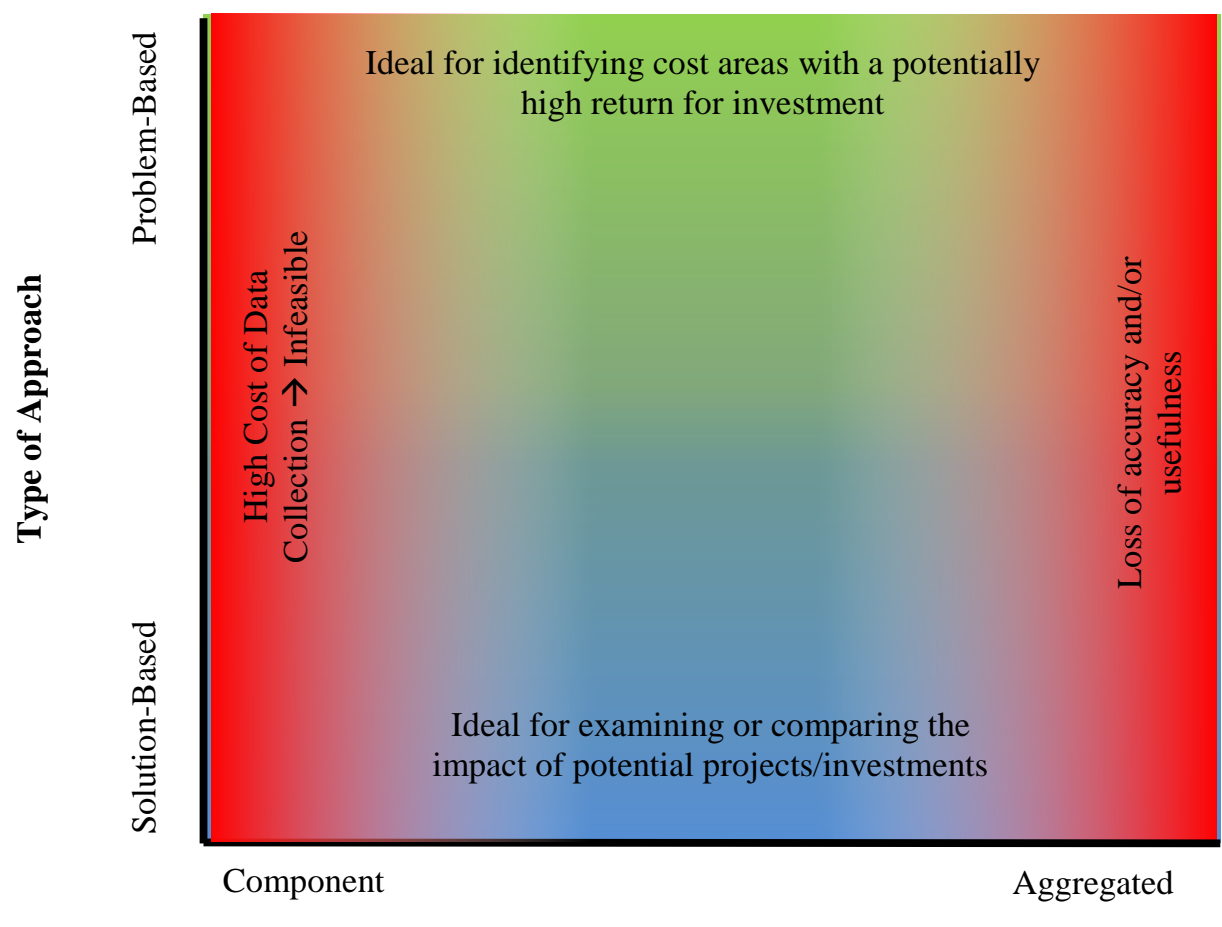

Level of Data Collection and/or Reporting

Figure 6: Categories of Cost Analysis 
A number of tactics were presented for measuring industry costs, including the following:

- An individual familiar with economic and/or cost data should be engaged in measuring industry costs.

- As many cost categories as possible should be measured, covering, if possible, the entirety of relevant economic activity (i.e., all manufacturing activities).

- Use a problem/cost-based focus to examine the costs that manufacturers face.

- When possible, measure the cost components rather than an aggregated total cost. 


\section{Step 3. Identify Potential Methods/Projects for Reducing Identified Costs/Impacts}

This step involves identifying potential projects to execute. This is likely to involve discussion and brain storming for new ideas. Frequently, people approach brainstorming as idle discussion or casual conversation. Research, referenced below, suggests a more deliberate approach is, likely, to have greater success in developing new ideas, as creativity is the result of hard work and not innate abilities.

One thing to consider is that when people generate ideas, the least innovative ones tend to come first, as these involve thoughts that are readily familiar to us. If the ideas during a brainstorm session were grouped into 3 chronological categories (i.e., first third, second third, and last third), the most creative are, typically, those in the last category. ${ }^{6}$ Moreover, one should not simply adopt the first good idea that comes about nor should the session be cut short.

Another issue to keep in mind is that mixing creativity with evaluation tends to result in less ideas. ${ }^{7}$ That is, an idea is proposed and then it is immediately critiqued. This creates multiple problems. The first issue is that it shifts the brains resources back and forth in a multitasking effort. This occurs because we are utilizing different parts of the brain. A more effective approach is to generate ideas while holding back critiquing them until a later time (i.e., deferring judgment). ${ }^{8,9,10}$ Focusing on idea creation allows the brain to gather momentum in creating new ideas and solutions rather than evaluating what ideas are the best. It also allows for synergy to develop within the group where one idea sparks other ideas.

The second problem of having both idea creation and evaluation during brainstorming is that it stifles willingness to share ideas. An environment where people share ideas, generally, requires them to feel free of being judged or criticized. If participants fear being embarrassed, they are less likely to share as there is some cost associated with it. So, before sharing, participants will expend a greater amount of their thoughts on the value of their idea rather than on generating ideas. In addition to the guidance above, there are a number of texts for brainstorming and developing new ideas that one might consult.

The potential research investments that a change agent could invest in can span a number of fields, including engineering, chemistry, physics, computer science, and economics. Given the nature of manufacturing, many of the research topics revolve around the natural sciences; however, a variety of disciplines are relevant. During brainstorming, the

\footnotetext{
${ }^{6}$ Puccio, Gerard. The Creative Thinker's Toolkit. (Chantilly, VA: Great Courses, 2014) 27

${ }^{7}$ Baer, John. Creativity and Divergent Thinking: A Task-Specific Approach. (Hillsdale, NJ: Lawrence Erlbaum Associates, 1993) 34-35.

${ }^{8}$ Puccio, Gerard. The Creative Thinker's Toolkit. (Chantilly, VA: Great Courses, 2014) 28

${ }^{9}$ Ness, Roberta. Innovation Generation: How to Produce Creative and Useful Scientific Ideas. (New York, NY: Oxford University Press, 2012) 159-161.

${ }^{10}$ Rickards, Tudor. Creativity and Problem Solving at Work. (Aldershot, England: Gower Publishing Company, 1990) 104-105.
} 
presence of experts in multiple fields of research can provide perspectives that might not have been revealed otherwise.

A number of tactics were presented to identify potential projects, including the following:

- One should not simply adopt the first good idea that comes about nor should a brainstorm session be cut short.

- Generate ideas while holding back critiquing them until a later time (i.e., deferring judgment).

- The presence of experts in multiple fields of research can provide perspectives that might not have been revealed otherwise. 


\section{Step 4. Evaluate Costs/Benefits using a Solution-Based Approach}

After identifying potential projects, it is necessary to measure the costs and benefits of the project. There are four major challenges that arise in this step: 1) absence of data, 2) uncertainty, 3) diffusion rate of a new technology/process, and 4) mixed units of measurement. There are many variables for which there is no data available. For example, there is limited data on the manufacturing defect rate due to production machinery maintenance. When there are estimates available for an analysis, there is often uncertainty associated with it. One of the common values of uncertainty is the rate at which new technologies and processes are adopted. Typically, research results in some new approach that manufacturers can adopt to improve production or sales. The rate of adoption affects the benefits of investing in the research. The last challenge is that some costs/benefits are measured in different units. For example, cost reduction is measured in dollars while environmental impact might be measured in carbon dioxide levels. Some method or common unit is needed to compare costs/benefits measured in different units. Below is a discussion of measuring costs and benefits along with the challenges that follow.

Measuring Costs/Benefits: The costs of an investment or research project are, typically, the expenditures needed to achieve the project goals. These include, but are not limited to, labor costs, materials, travel, equipment, and laboratory costs including laboratory space. These costs are incurred over a period of time often measured in years. as illustrated in Figure 7, the primary benefits of a research project in manufacturing include

Figure 7: Potential Economic Impact of Change Agent Research and Development in Manufacturing

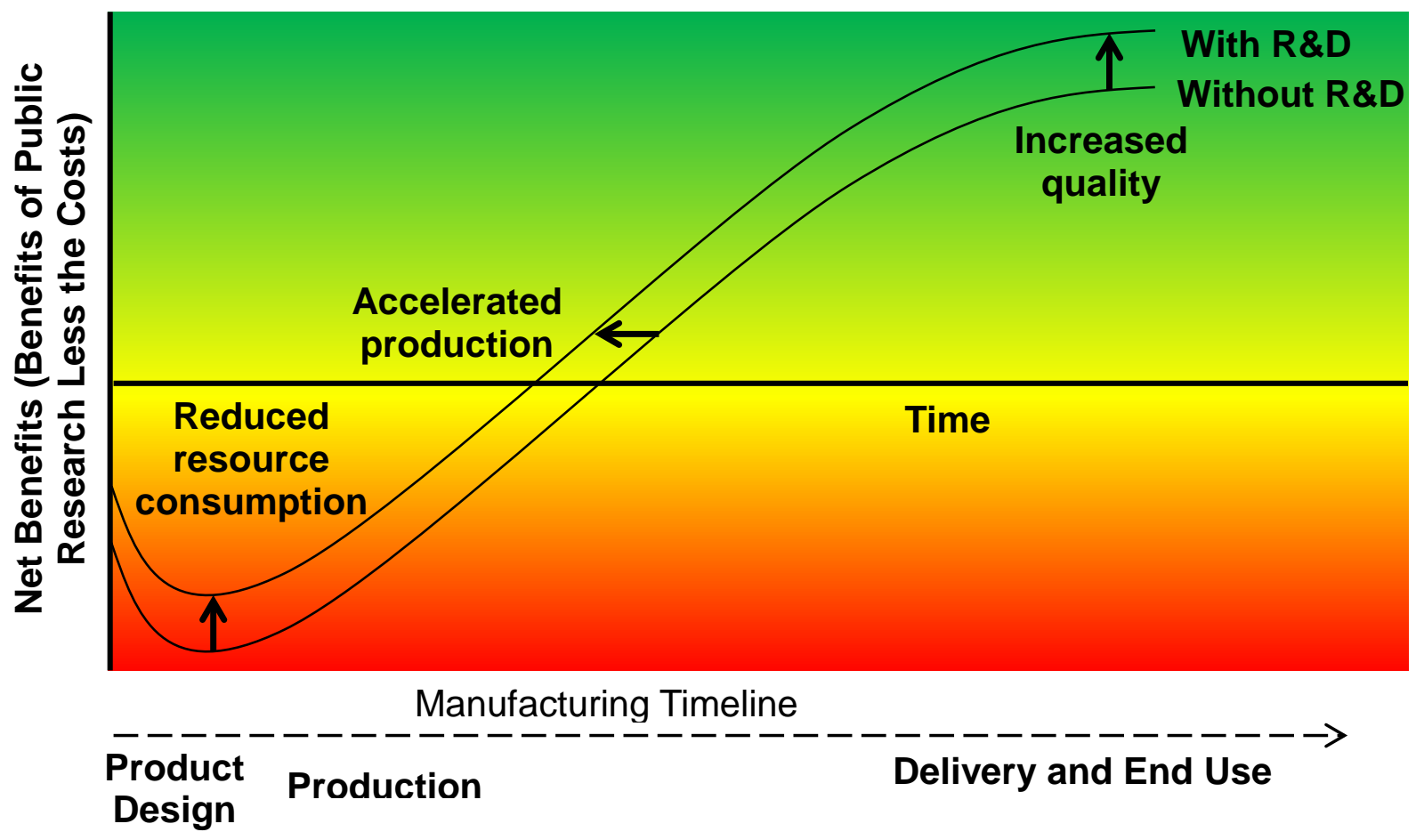


reduced resource consumption, accelerated production timelines, and increased quality/function. For instance, design data standards can reduce design costs by reducing the need to re-enter data (i.e., reduced resource consumption). Another example can be seen in advancing machinery maintenance that reduces machinery downtime and accelerates production. Improved maintenance can also result in improved product quality by reducing product defects. Similar to the costs of the project, the benefits are generated over a period of time often measured in years. If two or more potential projects have overlapping investments, the overlapping parts should be included in each project and treated as different scenarios. All values for both the costs and benefits need to be adjusted to a common year. This is the primary challenge addressed by some economic evaluation methods. Change agents can use accepted methods of investment analysis, such as internal rate of return and net present value, to evaluate potential projects. Below is a description of these approaches utilizing descriptions in NIST Advanced Manufacturing Series 200-5. ${ }^{11}$

Table 2: Survey Response to "How Frequently does your Firm use the Following Techniques when Deciding which Projects or Acquisitions to Pursue"

\begin{tabular}{lcc|cc|} 
& $\begin{array}{c}\text { \% always } \\
\text { or almost } \\
\text { always }\end{array}$ & $\begin{array}{c}\text { Average } \\
\text { Response\# }\end{array}$ & \multicolumn{2}{c|}{$\begin{array}{c}\text { Average Response by } \\
\text { Small }\end{array}$} \\
\hline Internal Rate of Return & 75.61 & 3.09 & 2.87 & Large \\
Net Present Value & 74.93 & 3.08 & 2.83 & $3.41^{* * * *}$ \\
Payback Period & 56.74 & 2.53 & 2.72 & $2.25^{* * *}$ \\
Hurdle Rate & 56.94 & 2.48 & 2.13 & $2.95^{* * *}$ \\
Sensitivity Analysis & 51.54 & 2.31 & 2.13 & $2.56^{* * *}$ \\
Earnings Multiple Approach & 38.92 & 1.89 & 1.79 & $2.01^{*}$ \\
Discounted Payback Period & 29.45 & 1.56 & 1.58 & 1.55 \\
We incorporate the "real options" of a & & & & \\
project when evaluating it & 26.59 & 1.47 & 1.4 & 1.57 \\
Accounting Rate of Return & 20.29 & 1.34 & 1.41 & 1.25 \\
Value-at-Risk or other Simulation & 13.66 & 0.95 & 0.76 & $1.22^{* * *}$ \\
Adjusted Present Value & 10.78 & 0.85 & 0.93 & 0.72 \\
Profitability Index & 11.87 & 0.83 & 0.88 & 0.75 \\
\hline$*$ Statistically Differe & & & & \\
\hline
\end{tabular}

* Statistically Different at the $1 \%$ level

** Statistically different at the $5 \%$ level

*** Statistically different at the $10 \%$ level

\# Respondents were asked on a scale from 0 (never use) to 4 (always use)

Source: Adapted from Graham, John and Campbell Harvey. "The Theory and Practice of

Corporate Finance: Evidence from the Field." Journal of Financial Economics 60 (2001): 187-

243.

\footnotetext{
11 Thomas, Douglas S. Investment Analysis Methods: A Practitioners Guide to Understanding the Basic Principles for Investment Decisions in Manufacturing. October 2017.

https://doi.org/10.6028/NIST.AMS.200-5
} 
Graham and Harvey (2001) provides some insight into the more prominent methods for investment analysis by surveying 392 chief financial officers (CFO) for firms listed in the Fortune 500 rankings about the cost of capital, capital budgeting, and capital structure. ${ }^{12}$ Approximately $40 \%$ of the firms were manufacturers and another $15 \%$ were financial. Respondents were asked on a scale from 0 to 4, "how Frequently does your Firm use the Following Techniques when Deciding which Projects or Acquisitions to Pursue.” It listed 11 techniques with 0 representing "never use it" and 4 meaning "always use it." The results are provided in Table 2, and include the percent who responded with 3 or 4 , average response, and average response by firm size. The most prominent methods used in economic decision making were internal rate of return and net present value with $76 \%$ and $75 \%$ of respondents always or almost always use each method, respectively. Small firms had lower responses for internal rate of return and net present value, which are considered by finance experts to be best practices, and higher responses for the payback method.

Although it has some limitations, internal rate of return is an intuitive method of analysis, as most people are familiar with estimating a rate of return. Net present value is considered the most accurate for decision making, as presented in most finance text books. Both of these approaches are discussed in Appendix A.3 through Appendix A.6. These approaches require an understanding of discount rates and adjusting for inflation; which are discussed in Appendix A.1 and Appendix A.2. Appendix A.7 through Appendix A.9 discuss some of the other approaches for investment analysis, which are typically considered to be supplements to net present value and the internal rate of return. Three approaches listed in Table 2 are not discussed in this document: value-at-risk, earnings multiple approach, and accounting rate of return. These approaches are not discussed as they tend to be less applicable to individual project decisions for the target audience of this report.

Each of the methods discussed in this report are applicable to certain decision types and have some limitations. Nearly all of the methods can be used in an accept/reject decision for an investment, as seen in Table 3. A selection of them can be used for making decisions regarding design and size of a project while fewer can be used to prioritize or rank investments. An example of the different types of investment decisions are shown in Table 4. A number of limitations and considerations apply to each of the methods, as seen in Table 5. Many of the approaches require an examination over the same study period or assuming that assets can be expected to repeat the cost/benefits of the original investment, as these methods do not consider information about the duration of a project.

Unknown Data: One of the leading problems with examining change agent investments is inadequate data. In manufacturing research, publicly available cost data is limited and the data available has caveats and limited applicability. For instance, the Annual Survey of Manufactures provides data on maintenance costs; however, this includes maintenance of both machinery and buildings, which are, likely, to involve different types of research

${ }^{12}$ Graham, John and Campbell Harvey. "The Theory and Practice of Corporate Finance: Evidence from the Field." Journal of Financial Economics 60 (2001): 187-243. 
projects. The data is also only for outsourced or purchased maintenance; so, internal costs, such as a maintenance department, is not included.

To address this problem, change agents can collect data, as previously discussed. Unfortunately, this might not always be possible, as time may not permit data collection or stakeholders (e.g., manufacturers) might be unwilling to share data. Thus, an alternative approach might need to be implemented. One such approach is to approximate reasonable boundaries for missing data. The reasonable boundaries approach involves first identifying the nearest measurable cost category. For example, consider a project that develops a data language to reduce having to re-enter design data when transferring design information between supply chain points. The amount of time saved from such an

Table 3: Application of Methods for Investment Analysis

\begin{tabular}{|c|c|c|c|c|c|c|c|c|c|}
\hline & 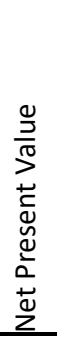 & 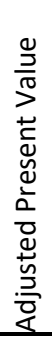 & 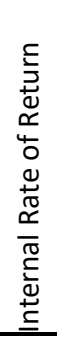 & 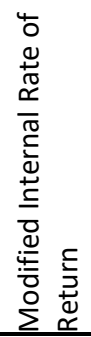 & 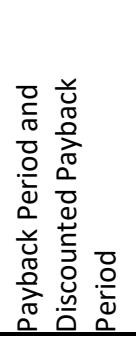 & 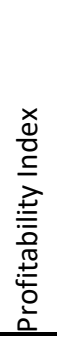 & 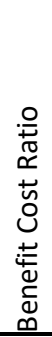 & 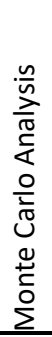 & 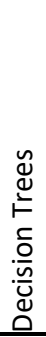 \\
\hline Accept/Reject & $x$ & $x$ & $x$ & $x$ & $x^{1}$ & $x$ & $x$ & & \\
\hline Design & $x$ & $x$ & $x^{2}$ & $x^{2}$ & & $x^{2}$ & $x^{2}$ & & \\
\hline Size & $x$ & $x$ & $x^{2}$ & $x^{2}$ & & $x^{2}$ & $x^{2}$ & & \\
\hline Priority or Ranking & & & $x$ & $x$ & & $x$ & $x$ & & \\
\hline $\begin{array}{l}\text { Uncertainty and } \\
\text { potential outcomes }\end{array}$ & & & & & & & & $x$ & $x$ \\
\hline
\end{tabular}

1: Note significant limitations

2: Appropriate when incremental discounted costs and benefits are considered (i.e., the difference in costs/benefits between two investments). To decide between more than two options, pairwise comparisons are necessary.

Table 4: Examples of Manufacturing Industry Investment Decisions

\begin{tabular}{|c|c|}
\hline Accept/Reject & $\begin{array}{l}\text { - Is an additive manufacturing project cost effective? } \\
\text { - Is the development of a new standard cost effective? } \\
\text { - Is the development of a new robotic system cost effective? }\end{array}$ \\
\hline Design & $\begin{array}{l}\text { - What robotic safety project is the most cost effective? } \\
\text { - What HVAC control project is the most cost effective? }\end{array}$ \\
\hline Size & $\begin{array}{l}\text { - What size laboratory for this project is cost effective? } \\
\text { - What size of machine is most cost effective a robotics project? }\end{array}$ \\
\hline Priority or Ranking & $\begin{array}{l}\text { - We have } 15 \text { proposed projects, but can only fund } 10 \text { of them, } \\
\text { which ones should we choose? } \\
\text { - We have five proposed investments but can only afford a } \\
\text { selection of them. Which investments do we choose? }\end{array}$ \\
\hline
\end{tabular}


investment might be unknown; however, the labor cost for engineers and machinists can be estimated using public data. These figures (i.e., labor cost for engineers and machinists) would be the next nearest measurable cost category.

The next step is to develop a boundary estimate for the next step down, moving toward the relevant cost item; that is, develop a boundary estimate for the next data item needed that moves closer to understanding the unknown component of interest. In this case, the next step is the proportion of time spent on re-entering data. This boundary must essentially be made by consulting literature and industry experts with the final values being an estimate of the highest and lowest possible values. Although this is not ideal, it is better to approximate parts of a project's return on investment rather than doing so for the entirety of the return on investment for the project. ${ }^{13}$ There is, generally, far greater error in using intuition or guessing which projects have a high return rather than approximating boundaries of subcomponents. ${ }^{14}$

Table 5: Limitations and Considerations of Methods for Investment Analysis

\begin{tabular}{|c|c|}
\hline Method & Limitation \\
\hline Net Present Value & Alternatives must be compared over the same study period. \\
\hline Adjusted Present Value & Alternatives must be compared over the same study period. \\
\hline Internal Rate of Return & $\begin{array}{l}\text { In some instances, inconsistent results may arise. This } \\
\text { calculation does not reveal information about the size or } \\
\text { duration of a project. Alternatives must be compared over } \\
\text { the same study period or it must be assumed that assets can } \\
\text { be expected to repeat the costs/benefits of the original } \\
\text { investment. }\end{array}$ \\
\hline Modified Internal Rate of Return & $\begin{array}{l}\text { This calculation does not reveal information about the size or } \\
\text { duration of a project. Alternatives must be compared over } \\
\text { the same study period or it must be assumed that assets can } \\
\text { be expected to repeat the costs/benefits of the original } \\
\text { investment. }\end{array}$ \\
\hline Payback Period and Discounted Payback Period & $\begin{array}{l}\text { Cash flows beyond the payback period are ignored. Projects } \\
\text { selected on this criterion may not be cost effective. }\end{array}$ \\
\hline Profitability Index & $\begin{array}{l}\text { This calculation does not reveal information about the size or } \\
\text { duration of a project. Alternatives must be compared over } \\
\text { the same study period or it must be assumed that assets can } \\
\text { be expected to repeat the costs/benefits of the original } \\
\text { investment. }\end{array}$ \\
\hline
\end{tabular}

\footnotetext{
${ }^{13}$ MacGregor, Donald G. “Decomposition for Judgmental Forecasting and Estimation.” In Armstrong, J. Scott. Principles of Forecasting: A Handbook for Researchers and Practitioners. (Norwell, MA: Kluwer Academic Publishers 2001): 107-123.

14 Tetlock, Philip and Dan Gardner. Super Forecasting: The Art and Science of Prediction. (New York, NY: Broadway Books, 2015).
} 
The next step is to develop boundary estimates for the next step down and continue down until one reaches the relevant cost item(s). In this case, the next step down would be the proportion of the time spent re-entering data that would be reduced due to the new data language. The series of subcomponent boundary estimates can then be used to calculate boundary estimates for the impact of the proposed project. For this example, that could be calculated as:

where

$$
E I_{S}=E * D R_{E, S} * R_{E, S}+M * D R_{M, S} * R_{M, S}
$$

$E I=$ Estimated impact $\mathrm{S}$, where $\mathrm{S}$ is either high or low boundary estimate

$E=$ Engineering labor cost

$M=$ Machinery labor cost

$D R_{x, S}=$ Proportion of time for data re-entry for $\mathrm{x}$ at $\mathrm{S}$, where $\mathrm{x}$ is either engineering or machinery labor and where $S$ is either high or low boundary estimate

$R_{x, S}=$ Proportion of data re-entry time reduced by new data language for $\mathrm{x}$ at $\mathrm{S}$, where $\mathrm{x}$ is either engineering or machinery labor and where $\mathrm{S}$ is either high or low boundary estimate

The final step is to apply methods of examining uncertainty, as discussed below.

Uncertainty: Many variables have some level of uncertainty. For instance, the price of energy fluctuates over time and might impact the costs or benefits of a particular project. One method for examining uncertainty is to measure the range (i.e., maximum and minimum) of costs and benefits. These could then be combined to estimate the range of net benefits, internal rate of return, and other measures discussed in Appendix A.

An additional option is to graph the range of cost and benefits for each project. This will give a visual aid for identifying relative rankings, as illustrated in Figure 8. The benefit cost ratio for projects can be visually examined by drawing a line from the origin through the top right corner of the projects graph and another through the bottom right corner, as illustrated for Project A in Figure 8. Because the slope of the line represents a constant benefit cost ratio at the intersecting point of the project, any projects, or portions thereof, that lie above and to the left of the upper line outranks the project. So, Project E and Project B outrank Project A. Any projects that lie below and to the right of the lower line are outranked. So, Project A outranks Project D. Projects that lie between the upper and lower lines have overlapping benefit cost ratios with Project A. Net present value and internal rate of return are still key measures for economic decision making, though. Net present value relationships can be revealed by drawing a 45-degree line through the top left and bottom right points of the project graph, as shown in Figure $9 .{ }^{15}$ Because this line represents a 1 to 1 change in costs and benefits, the line represents constant net present value; so, those projects that lie above the line have higher net present value and those that lie below the lower line have lower net present value.

15 This assumes the $\mathrm{x}$-axis and $\mathrm{y}$-axis have the same scale so that a 45 degree line represents step changes of 1 unit in cost by 1 unit in benefit. 
Figure 8: Graphing Costs and Benefits: Examining Benefit-Cost Ratio (BCR)

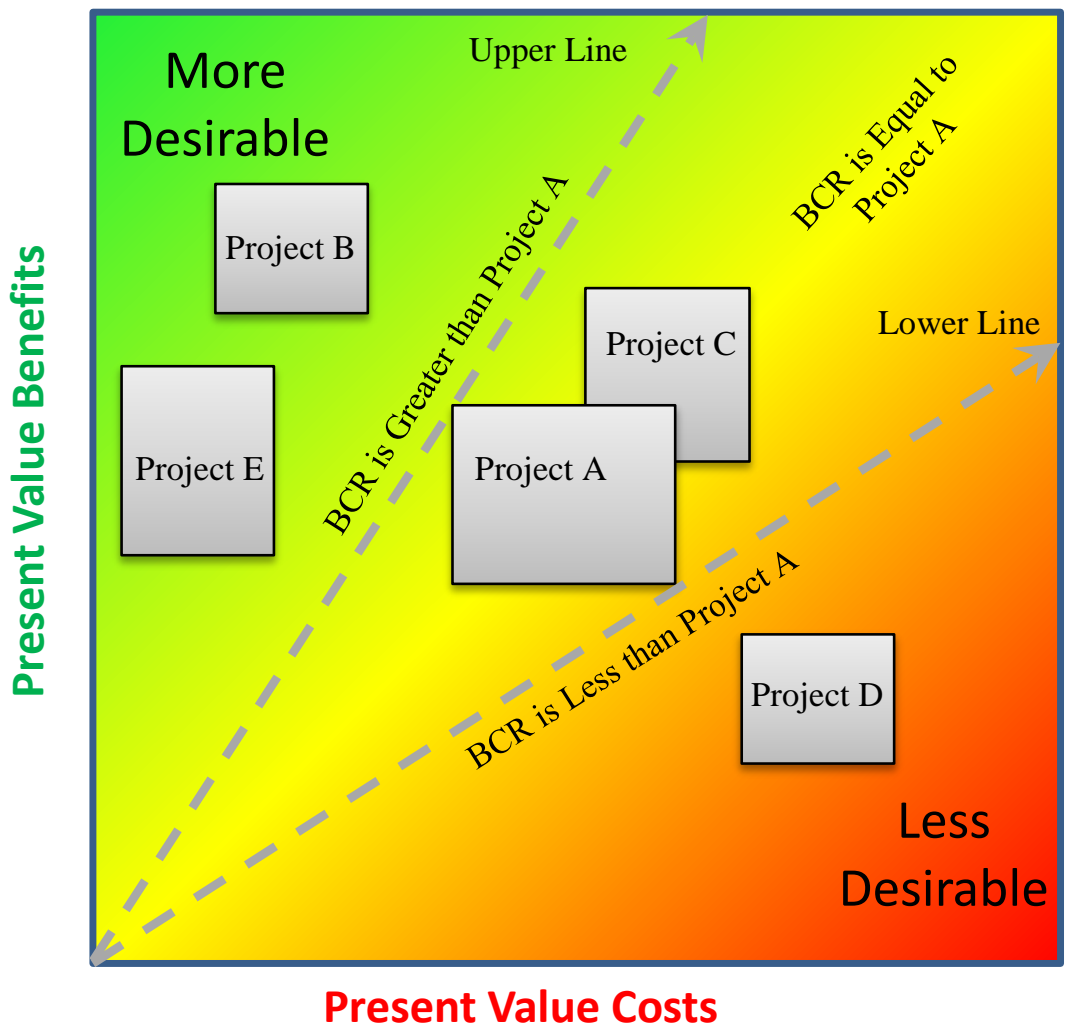

Figure 9: Graphing Costs and Benefits: Examining Net Present Value

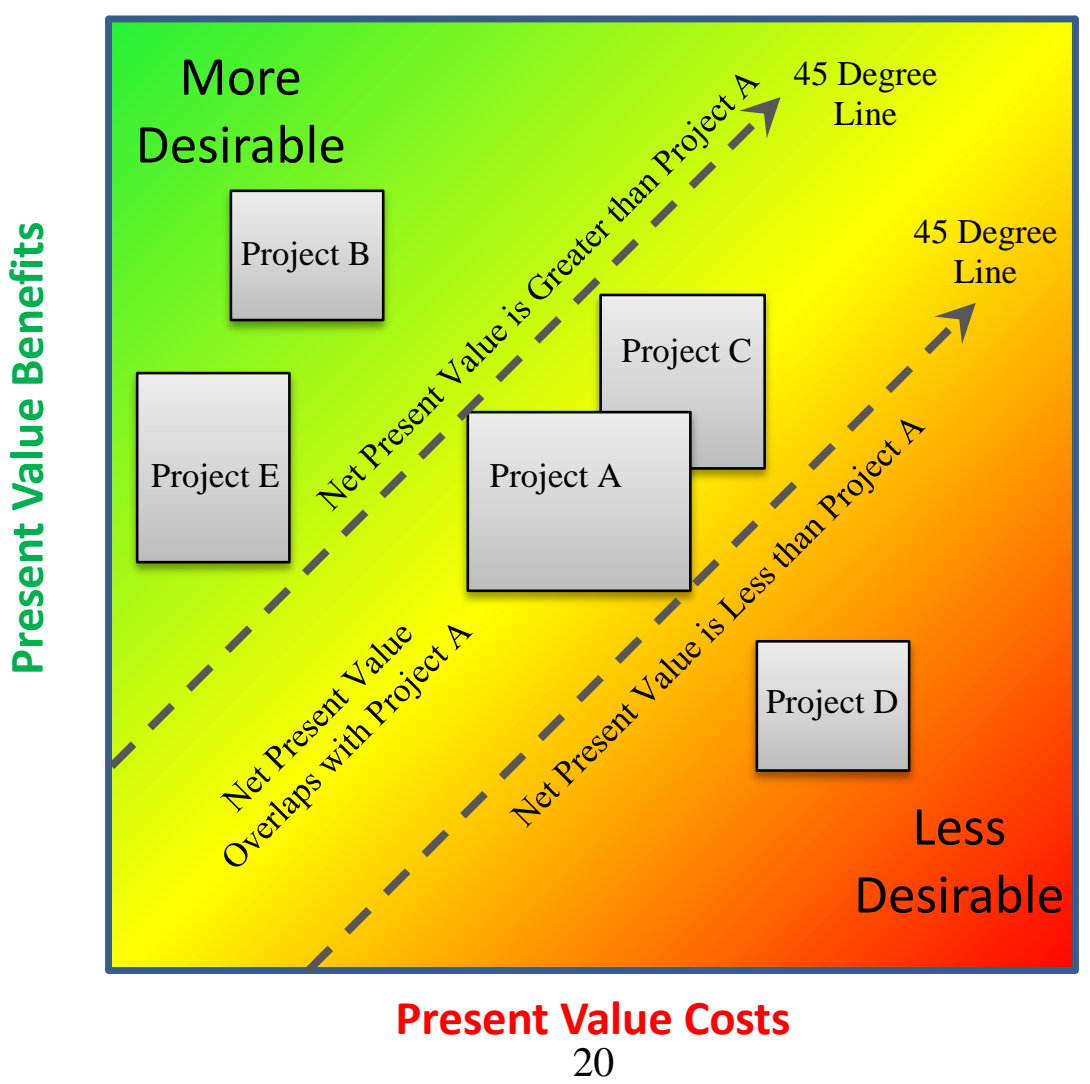


The internal rate of return cannot be revealed as easily graphically, as it requires identifying the discount rate where costs and benefits are equal, as illustrated in Figure 10. In the case of uncertain variables, one might estimate the maximum and minimum possible values for the internal rate of return for each project. These can then be compared across projects.

A more mathematically rigorous approach is to use Monte Carlo analysis, which is a probabilistic sensitivity analysis, to address uncertainty, as described in Appendix B. It generally requires a software tool, which will randomly sample from user selected probability distributions for each input variable of interest. One issue that arises in this approach is selecting the type of distribution for the variable. It is often the case that a variable is uncertain due to data constraints, which means it is unlikely that the distribution of this variable is known. In these cases, it is better to approximate the distribution using informed judgement. This approach will likely provide more insight than the alternative, which is to not conduct a sensitivity analysis.

Despite best efforts, there will be some projects for which the impact will be largely unknown. One example is regarding projects in additive manufacturing where there is wild speculation about the extent and impact of its future adoption and use. The adoption rate of additive manufacturing is largely unknown; thus, is unclear what the impact of investing research into this topic area will be. Despite this obstacle, it is better to estimate or approximate unknown values using best judgement. The goal of an economic

Figure 10: Illustration of Internal Rate of Return

Benefits

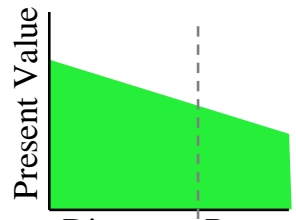

Internal rate of return (IRR) is the discount rate where present value benefits
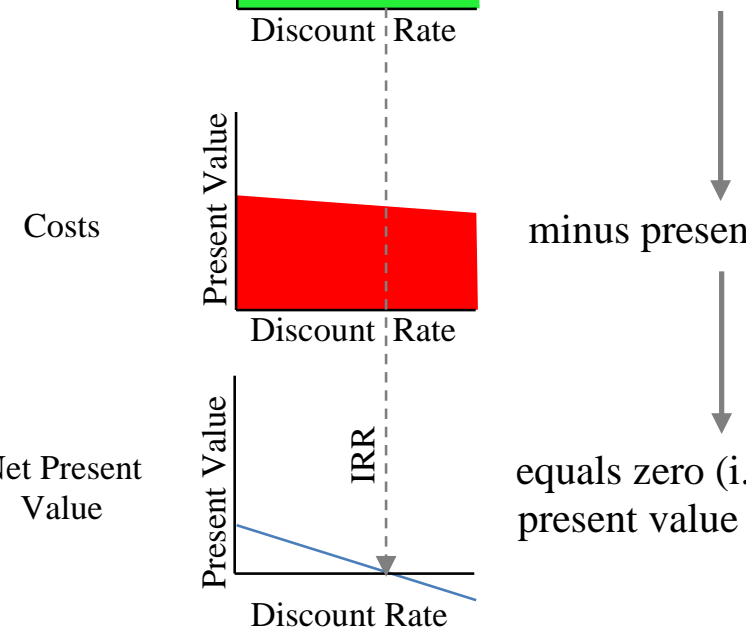

minus present value costs

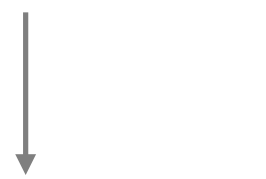

equals zero (i.e., where net present value equals zero).
NOTE: In the case of uncertainty, the maximum and minimum internal rate of return might be calculated to provide a range for each project, as illustrated below.

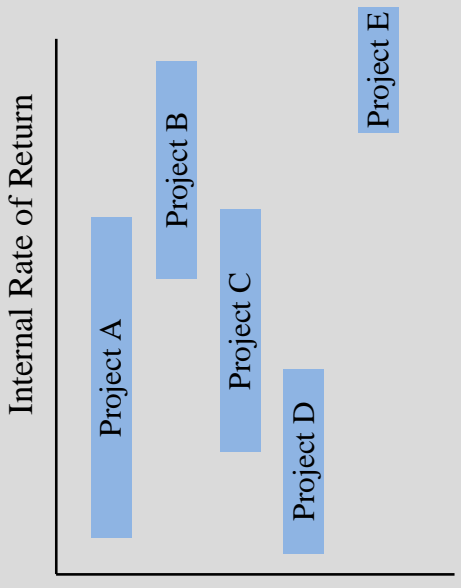


assessment for decision making should not be seen as 1) it is precise and we use it or 2) it has large error and it has no use. Rather, it should be seen as best practices for decision making given the data and information that is available. A best practice is to try to objectively quantify the variables to the best of our ability given the data and information at hand. This reduces the potential for errors in logic and judgement that humans frequently engage.

Adoption and Diffusion of New Technologies/Processes: When making an economic assessment of a change agent research project, the benefits often rely on the adoption and diffusion rate of a new standard or technology (i.e., the rate at which people and businesses implement the new standard/technology); however, the rate of adoption is, typically, unknown, but some studies have quantified adoption rates. For example, Rogers (1995) proposes a logistic S-curve model of diffusion, where at the early stage of diffusion there is an increasing rate, as seen in Figure $11 .{ }^{16}$ Toward the end of the diffusion curve there is a decreasing rate. Early adopters of a new technology are at the left side of the curve while late adopters are at the right end. There are often great benefits for early adopters, but they are frequently accompanied with great risks.

Figure 11: Logistic S-Curve Model of Diffusion

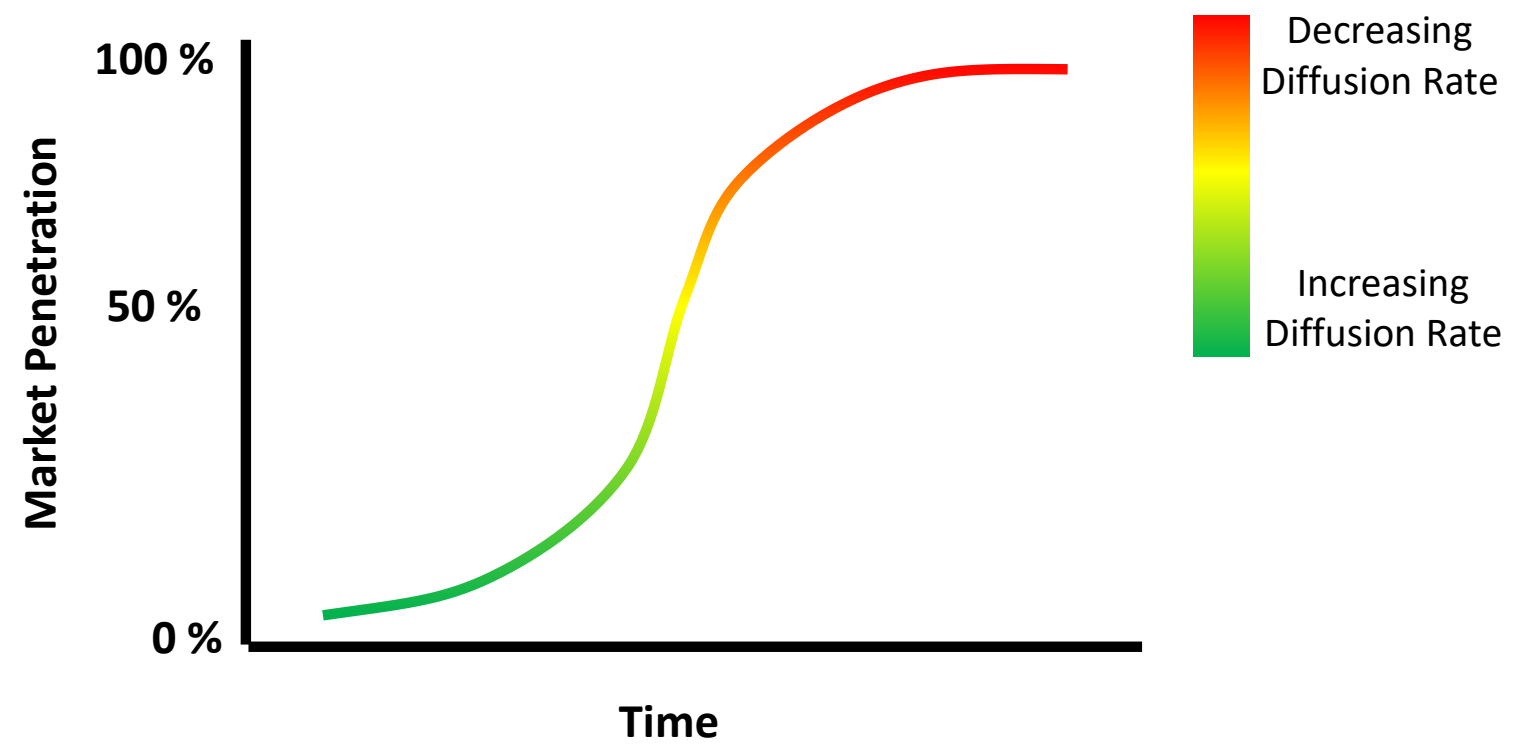

Modified from Rogers, E. M. 1995. Diffusion of Innovations. Fourth Edition (New York: The Free Press, 1995) 258.

\footnotetext{
${ }^{16}$ Rogers, E. M. Diffusion of Innovations. Fourth Edition (New York: The Free Press, 1995) 258.
} 
Several factors can affect how a new technology propagates through an industry or business community. The communication structure, for example, affects how people hear about a new technology. The average size of firms in an industry affects their ability to adopt new technologies, as they might not have the resources to invest in it. Rogers proposed several variables that affect the adoption and diffusion of a new technology ${ }^{17}$ :

o Perceived attributes of innovations

o Relative advantage to the adopter

o Compatibility with other currently used products and processes

o Complexity for the adopter

o Trialability of the new technology

o Observability of the results of an innovation

o Information dissemination

o Nature of the social system (e.g. attitudes, beliefs, etc.)

0 Extent of change agent promotion efforts

o Producer ability/profitability of adoption

The change in capabilities along with these other factors that affect the adoption of a new technology are considered when contemplating adoption. For example, a firm needs to consider whether its staff can adapt to the new technology or if the new technology is compatible with their technology infrastructure. These issues may result in underestimating costs and/or overestimating benefits.

An economic assessment of a research investment in applied manufacturing will, in many cases, need to consider not only how they will facilitate adoption and diffusion, but estimate the rate of adoption and diffusion. This is a factor that may need to be incorporated into an uncertainty analysis.

Mixed Units of Measurement: The last challenge discussed in Step 4, is the problem of an investment that has costs/benefits that are in different units. For example, consider a project that reduces both the dollar costs of production and the associated environmental impact. The typical approach to address this problem is to convert the values to a common unit. For example, units of carbon, measuring environmental impact, are frequently converted to a dollar value. Another approach is to use the Analytical Hierarchy Process to create relative weights when there are costs/benefits measured in different units. In some cases, the different attributes are brought together into 2 units (e.g., dollars and units of carbon). An evaluation of tradeoffs is then necessary.

Summary: A number of approaches and issues were discussed for Step 4, including the following:

- There are four major challenges that arise in this step: 1) absence of data, 2) uncertainty, 3) diffusion rate of a new technology/process, and 4) mixed units of measurement.

\footnotetext{
${ }^{17}$ Rogers, E. M. Diffusion of Innovations. Fourth Edition (New York: The Free Press, 1995) 258.
} 
- Change agents can use accepted methods of investment analysis, such as internal rate of return and net present value, to evaluate potential projects.

- Approximate reasonable boundaries for missing data.

- Graph the range of cost and benefits for each project.

- Use Monte Carlo analysis, a probabilistic sensitivity analysis, to address uncertainty.

- An economic assessment of a change agent research investment in applied manufacturing will, in many cases, need to consider the rate of adoption and diffusion of a new technology.

- Use the Analytical Hierarchy Process to create relative weights when there are costs/benefits measured in different units. 


\section{Step 5.Select projects based on economics, capabilities, and other factors}

A benefit of using measurable criteria, such as those in an economic assessment, is that it can put downward pressure on costs and upward pressure on benefits. Researchers are often tempted or even incentivized to increase the amount of resources their project consumes, as this can garner more individual attention and rewards but not necessarily higher economic performance. Moreover, without an economic assessment, there is limited incentive to conserve resources below the budget constraint. There are some additional factors to consider, including when to use intuition, diminishing returns, diversifying, factors that might be excluded from an analysis, and inciting internal competition. These items are briefly discussed below.

Intuition: There is a temptation or even a tendency for decision makers to use their instinct or intuition to determine which projects to invest. To some extent this should be resisted, as humans are vulnerable to being heavily influenced by immaterial feelings and emotions. ${ }^{18,19}$ For instance, a project might seem more appealing to a decision maker because they are better friends with the researcher. Research has shown that even having heard uninformative numbers can influence our judgement. ${ }^{20}$ Many economic researchers have investigated these phenomena, including Daniel Kahneman, who won the Nobel Prize in economics for his work in this area. Despite one's best efforts, it has been shown that humans are not able to completely separate emotions from logical decision making. ${ }^{21,22}$ The influence is nearly inescapable.

When intuition is broad and fuzzy it is more vulnerable to being based on unsound reasoning. If it is necessary to use intuition, it should be on the evaluation of specific factors of an investment. For instance, if a particular cost of an investment is unknown, one might use individual insight to surmise the value of this cost rather than using intuition to evaluate the entirety of the project and whether it warrants investment.

Diminishing Returns and Diversification: Another item to consider is often encapsulated in the saying, “don't put all your eggs in one basket.” A manager once asked, if Project X has such a high return, why don't we eliminate other projects and invest those resources back into Project $X$ ? There are two reasons why one might invest in multiple projects when one has higher returns: 1) diminishing returns and 2) the risk of the project failing. Diminishing returns refers to the idea that, at some point, an additional dollar of investment results in lower incremental per-unit returns. The first million dollars of investment may have a high return, but that does not mean the second million will also have a high return. So, as one invests more and more into a project, it can drag down the

\footnotetext{
${ }^{18}$ Kahneman, Daniel. Thinking, Fast and Slow. (New York: Farrar, Straus, and Giroux, 2011).

${ }^{19}$ Ariely, Dan. Predictably Irrational: The Hidden Forces that Shape our Decisions. (New York, NY: Harper, 2008).

${ }^{20}$ Wilson, T. D., Houston, C. E., Etling, K. M., \& Brekke, N. (1996). A new look at anchoring effects: Basic anchoring and its antecedents. Journal of Experimental Psychology: General, 125(4), 387-402. http://dx.doi.org/10.1037/0096-3445.125.4.387

${ }^{21}$ Kahneman, Daniel. Thinking, Fast and Slow. (New York: Farrar, Straus, and Giroux, 2011).

${ }^{22}$ Ariely, Dan. Predictably Irrational: The Hidden Forces that Shape our Decisions. (New York, NY: Harper, 2008).
} 
return on investment (i.e., net present value, benefit cost ratio, and internal rate of return). Thus, the question of which project to invest in is accompanied by the question of how much should be invested. The second issue is that the successful project may turn and fail. No matter how confident we are about the future of a project, there is some risk of it failing. This risk is why it is beneficial to diversify research investments.

Additional Factors: Although an economic analysis might tend to be deterministic, there are, generally, items left to the discretion of management that might alter an investment decision. These items might include the probability of success for a particular investment, project leader ability, re-evaluating unknown/uncertain variables, the field/level of staff expertise relevant to an investment, and the relevance of an investment to the organization's mission, to name a few. Some of these items could also be incorporated into an economic analysis in the form of probabilities in a decision tree, as discussed in Appendix A. Alternatively, one could use the Analytical Hierarchy Process to weigh different factors. It is important to remember that an economic analysis of a project is a model and forecast of future economic events and, like all models and forecasts, there are limitations to the insights that are drawn from it. If it is the case that an investment decision is made using factors other than those in an economic assessment, management might consider being transparent about what the factors are, as this will allow future project proposals to improve and become more desirable.

Internal Competition: Given the observed benefits of competition, some managers are tempted to intensify internal competition within an organization using economic assessments, divisive language, and other means; however, some caution is warranted here. While evidence suggests that competition between companies often spurs productivity, internal competition can damage productivity ${ }^{23,24}$ and can serve as a barrier to adopting economic analyses. Competition is a useful tool for generating motivation; however, it is often at the cost of cooperation and/or collaboration. If employees are already well motivated, emphasizing and intensifying competition may only bring decreased productivity. Employees can increase relative performance through multiple means, including risky/costly illegal or unethical behavior, sabotaging other staff, withholding information, and other damaging behavior. Strong competitive pressure can and, frequently, does result in some of these tactics. Additionally, employees may resist the adoption of economic analyses due to increased internal competition. The more effective message regarding economic assessment and project selection might be that the selected projects achieve our goals more effectively and at lower costs. This message might direct researchers toward developing projects that further improve return on investment while maintaining the benefits of collaboration/cooperation.

Summary: A number of approaches and issues were presented for selecting projects with potentially high returns, including the following:

\footnotetext{
${ }^{23}$ Steinhage, Anna, Dan Cable, and Duncan Wardley. “The Pros and Cons of Competition Among Employees.” March 20, 2017. Harvard Business Review. https://hbr.org/2017/03/the-pros-and-cons-ofcompetition-among-employees .

${ }^{24}$ DuBois, Shelley. “Internal Competition at Work: Worth the Trouble?” January 25, 2012.

https://fortune.com/2012/01/25/internal-competition-at-work-worth-the-trouble/
} 
- A benefit of using measurable criteria, such as those in an economic assessment, is that it can put downward pressure on costs and upward pressure on benefits.

- Without an economic assessment, there is little incentive to conserve resources below the budget constraint.

- If it is necessary to use intuition, it should be on the evaluation of specific factors of an investment.

- Don't put all your eggs in one basket.

o As one invests more and more into a project, it can drag down the return on investment (i.e., net present value, benefit cost ratio, and internal rate of return).

o No matter how confident we are about the future of a project, there is some risk of it failing.

- Although an economic analysis might tend to be deterministic, there are, generally, items left to the discretion of management that might alter an investment decision.

- It is important to remember that an economic analysis of a project is a model and forecast of future economic events and, like all models and forecasts, there are limitations to the insights that are drawn from it.

- Some managers are tempted to intensify internal competition within an organization using economic assessments. While evidence suggests that competition between companies often spurs productivity, internal competition can damage productivity. 


\section{Works Cited}

Block, Stanley. “Are 'Real Options; Actually Used in the Real World?” The Engineering Economist. 2007 52(3) 255-267.

Brealey, Richard and Stewart Myers. Principles of Corporate Finance. 6th ed. New York, NY: McGraw-Hill, 2000. 583-666

Brealey, Richard, Stewart Myers, and Franklin Allen. Principles of Corporate Finance. 11th ed. New York, NY: McGraw-Hill, 2014.

Budnick, Frank. Applied Mathematics for Business, Economics, and the Social Sciences. New York, NY: McGraw-Hill, 1988. 894-895.

Bureau of Labor Statistics. Consumer Price Index. https://www.bls.gov/cpi/

Bureau of Labor Statistics. Producer Price Index. https://www.bls.gov/ppi/

Copeland, Tom and Vladimir Antikarov. Real Options: A Practitioner's Guide. United Kingdom: Thompson Corporation, 2003.

Defusco, Richard, Dennis McLeavey, Jerald Pinto, and David Runkle. Quantitative Investment Analysis. Hoboken, NJ: John Wiley and Sons, 2015. 2-3.

Defusco, Richard, Dennis McLeavey, Jerald Pinto, and David Runkle. Quantitative Methods for Investment Analysis. Baltimore, MD: United Book Press, Inc, 2001. 2.

Deutschman, Alan. Change or Die: The Three Keys to Change at Work and in Life. New York, NY: Harper Business, 2007.

Gordon, Judith R. Organizational Behavior: A Diagnostic Approach. Upper Saddle River, NJ: Prentice Hall, 2002). 465.

Graham, John and Campbell Harvey. "The Theory and Practice of Corporate Finance: Evidence from the Field." Journal of Financial Economics 60 (2001): 187-243.

Harris, C. M. Issues in Sensitivity and Statistical Analysis of Large-Scale, ComputerBased Models, NBS GCR 84-466, Gaithersburg, MD: National Bureau of Standards, 1984.

Helfert, Erich A. Financial Analysis: Tools and Techniques: A Guide for Managers. New York, NY: McGraw Hill, 2001. 235.

Kim, Bowon and Chulsoon Park. 2013. "Firms' Integrating Efforts to Mitigate the Tradeoff Between Controllability and Flexibility." International Journal of Production Research 51 (4):1258-1278. 
Kim, Bowon. 2015. Supply Chain Management: A Learning Perspective: Coursera Lecture. Korea Advanced Institute of Science and Technology.

Koebel, C. Theodore, Maria Papadakis, Ed Hudson, Marilyn Cavell. 2004. The Diffusion of Innovation in the Residential Building Industry. Upper Marlboro, MD: Center for Housing Research, Virginia Polytechnic Institute and State University and NAHB Research Center.

Kreitner, Robert and Angelo Kinicki. Organizational Behavior. 10th edition. New York, NY: McGraw-Hill/Irwin, 2013.

Lin, Steven. “The Modified Internal Rate of Return and Investment Criterion.” The Engineering Economist. 1976. 21(4) 237-247.

McKay, M. C., Conover, W. H., and Beckman, R.J. “A Comparison of Three Methods for Selecting Values of Input Variables in the Analysis of Output from a Computer Code,” Technometrics 21 (1979): 239-245.

Oracle. Crystal Ball, Crystal Ball 11.1.2.3 User Manual. Denver, CO: Decisioneering, Inc, 2013.

Rogers, E. M. 1995. Diffusion of Innovations. Fourth Edition (New York: The Free Press, 1995) 258.

Ross, Stephen, Randolph Westerfield, and Jeffrey Jaffe. Corporate Finance. New York, NY: McGraw-Hill, 2005. 146-149.

Scaccia, Jonathan P., Brittany S. Cook, Andrea Lamont, Abraham Wandersman, Jennifer Castellow, Jason Katz, and Rinad S. Beidas. 2015. “A Practical Implementation Science Heuristic for Organizational Readiness: R=MC2. Journal of Community Psychology 43(4). 484-501.

Thompson, Rob. Manufacturing Processes for Design Professionals. New York, NY: Thames \& Hudson, 2015.

Todd, Robert H., Dell K. Allen, and Leo Alting. Manufacturing Processes Reference Guide. New York, NY: Industrial Press, Inc, 1994. xiii-xxiv.

Unit Manufacturing Process Research Committee, National Research Council. Unit Manufacturing Processes: Issues and Opportunities in Research. Washington DC: The National Academic Press, 1995.

US Census Bureau. North American Industry Classification System. $<$ http://www.census.gov/eos/www/naics/>

Van Putten, Alexander and Ian MacMillan. "Making Real Options Really Work.” Harvard Business Review. December 2004. https://hbr.org/2004/12/making-real-optionsreally-work 
Victoria, Scott C., Tara Kenworthy, Erin Godly-Reynolds, Gilberte Bastien, Jonathan Scaccia, Courtney McMickens, Sharon Rachel, Sayon Cooper, Glenda Wrenn, and Abraham Wandersman. The Readiness for Integrated Care Questionnaire (RICQ): An Instrument to Assess Readiness to Integrate Behavioral Health and Primary Care. American Journal of Orthopsychiatry. April 10, 2017. 


\section{Appendix A: Supplemental Explanation of Economic Methods}

This appendix utilizes descriptions in NIST Advanced Manufacturing Series 200-5 to discuss methods for conducting an economic assessment. ${ }^{25}$

\section{A.1. Discount Rate}

A discount rate is sometimes referred to as a hurdle rate, interest rate, cutoff rate, benchmark, or the cost of capital. ${ }^{26,27}$ Many firms have a fixed discount rate for all projects; however, if a project has a higher level of risk, one should use a higher discount rate commensurate with that risk. This is similar to loaning money to someone who has an elevated likelihood of not paying the loan back. Typically, this person is charged a higher interest rate. Selecting a discount rate is, for many, a challenge. It is, typically, greater than or equal to the return on other readily available investment opportunities (e.g., stocks and bonds). It is, essentially, the minimum rate of return that one would need to engage in a particular investment (e.g., $10 \%$ annual return, $12 \%$ annual return, or higher). One method for selecting a discount rate is the weighted-average cost of capital, which is discussed by Brealey et al. ${ }^{28}$ If there is uncertainty about selecting a rate, one might also use a range for a discount rate (e.g., $9 \%$ to $12 \%$ ) and calculate two or more estimates for the net present value or conduct a Monte Carlo simulation as discussed in Appendix B.

\section{A.2. Adjusting for Inflation}

Some costs increase over time. For example, household energy costs increased $7.9 \%$ between 2006 and 2016. The change in prices is tracked by the Bureau of Labor Statistics and provided to the public in two forms: consumer price index and the producer price index. The consumer price index is a "measure of the average change over time in the prices paid by urban consumers for a market basket of consumer goods and services." 29 The Bureau of Labor Statistics (BLS) provides estimates for individual categories (e.g., energy) and an average for all goods. The producer price index is a "family of indexes that measures the average change over time in the selling prices received by domestic producers of goods and services." 30 Thus, the consumer price index is more appropriate for estimating the increase in the cost of goods while the producer price index is more appropriate for estimating the revenue received for a good. Both are provided as an index with a base year equaling 100 allowing one to estimate the increase in price between any

\footnotetext{
25 Thomas, Douglas S. Investment Analysis Methods: A Practitioners Guide to Understanding the Basic Principles for Investment Decisions in Manufacturing. October 2017. https://doi.org/10.6028/NIST.AMS.200-5

${ }^{26}$ Defusco, Richard, Dennis McLeavey, Jerald Pinto, and David Runkle. Quantitative Methods for Investment Analysis. Baltimore, MD: United Book Press, Inc, 2001. 2.

${ }^{27}$ Brealey, Richard and Stewart Myers. Principles of Corporate Finance. $6^{\text {th }}$ ed. New York, NY: McGrawHill, 2000. 17.

${ }^{28}$ Brealey, Richard, Stewart Myers, and Franklin Allen. Principles of Corporate Finance. $11^{\text {th }}$ ed. New York, NY: McGraw-Hill, 2014.

${ }^{29}$ Bureau of Labor Statistics. Consumer Price Index. https://www.bls.gov/cpi/

${ }^{30}$ Bureau of Labor Statistics. Producer Price Index. https://www.bls.gov/ppi/
} 
two years. For example, the consumer price index for household energy went from 189.286 in 2010 to 193.648 in 2011, which amounts to a $2.2 \%$ increase:

$$
2.2 \%=\left[\left(\frac{193.648}{189.286}\right)-1\right] * 100 \%
$$

This value provides some estimate of the increase in prices that might be expected in the future.

\section{A.3. Present Value}

A critical concept for evaluating an investment decision is the time value of money; that is, the relationship between cash flows occurring at different time periods. For example, receiving \$1000 today is typically preferred to receiving \$1000 one year from now. In order to compare these two cash flows occurring at different dates, the future cash flow is discounted to equate its value to cash flows received today. ${ }^{31,32}$ This is done by dividing the future cash flow by an interest rate or discount rate:

Equation 1

$$
P V_{1}=\frac{C F_{1}}{1+r}
$$

Where

$P V_{1}=$ Present value of future cash flow after one year

$C F_{1}=$ Cash flow after one year

$r=$ Discount rate which is, typically, between 0 and 1

The discount rate can be illustrated by considering how much one would need to be compensated to loan $\$ 1000$ to someone for one year. If that value is $\$ 100$, then the interest rate is $10 \%$, which is the discount rate. The $\$ 1100$ dollars that would be received in one year is equivalent to $\$ 1000$ today when discounted using Equation 1 and the $10 \%$ discount rate.

To calculate present value for cash flows after multiple years, the numerator in Equation 1 is raised to the power of the number of years that have passed:

Equation 2

$$
P V_{t}=\frac{C F_{t}}{(1+r)^{t}}
$$

\footnotetext{
${ }^{31}$ Ross, Stephen, Randolph Westerfield, and Jeffrey Jaffe. Corporate Finance. New York, NY: McGrawHill, 2005. 61.

32 Defusco, Richard, Dennis McLeavey, Jerald Pinto, and David Runkle. Quantitative Investment Analysis. Hoboken, NJ: John Wiley and Sons, 2015. 2-3.
} 
Where

$P V_{t}=$ Present value of future cash flow after number of $t$ years

$C F_{t}=$ Cash flow in year $\mathrm{t}$

$r=$ Discount rate which is, typically, between 0 and 1

\section{A.4. Net Present Value}

Net present value is the difference between the present value of all cash inflows and the present value of all cash outflows over the period of the investment. ${ }^{33,34,35}$ Net present value, which accounts for the time value of money, is a common metric for examining an investment, and is considered a superior method over other approaches. ${ }^{36,37}$ Other approaches often have caveats, do not consider all cash flows, or do not consider the time value of money. Net present value is calculated by taking each monetary cost and benefit associated with an investment and adjusting it to a common time period, which we will call time zero. The adjustment is for the time value of money, as described above. In addition to the time value of money, there is also the decreased purchase power of money due to inflation. The inflows are summed together and the outflows (costs) are subtracted resulting in the net present value:

Equation 3

$$
N P V=-C_{0}+I_{0}+\frac{-C_{1}}{(1+r)}+\frac{I_{1}}{(1+r)}+\frac{-C_{2}}{(1+r)^{2}}+\frac{I_{2}}{(1+r)^{2}} \cdots \frac{-C_{T}}{(1+r)^{T}}+\frac{I_{T}}{(1+r)^{T}}
$$

Where:

$I_{t}=$ Total cash inflow in time period $t$

$C_{t}=$ Total cost in time period $\mathrm{t}$

$r=$ Discount rate

$t=$ Time period, which is typically measured in years

Or, written another way

\footnotetext{
${ }^{33}$ Defusco, Richard, Dennis McLeavey, Jerald Pinto, and David Runkle. Quantitative Methods for Investment Analysis. Baltimore, MD: United Book Press, Inc, 2001. 54-56

${ }^{34}$ Budnick, Frank. Applied Mathematics for Business, Economics, and the Social Sciences. New York, NY: McGraw-Hill, 1988. 894-895.

${ }^{35}$ Defusco, Richard, Dennis McLeavey, Jerald Pinto, and David Runkle. Quantitative Investment Analysis. Hoboken, NJ: John Wiley and Sons, 2015. 44-45.

${ }^{36}$ Ross, Stephen, Randolph Westerfield, and Jeffrey Jaffe. Corporate Finance. New York, NY: McGrawHill, 2005. 223.

${ }^{37}$ Helfert, Erich A. Financial Analysis: Tools and Techniques: A Guide for Managers. New York, NY: McGraw Hill, 2001. 235.
} 
Equation 4

$$
N P V=\sum_{t=0}^{T} \frac{\left(I_{t}-C_{t}\right)}{(1+r)^{t}}
$$

The net cash inflows for each time period are divided by one plus a selected discount rate raised to the power of the time period, $t$. One challenge with net present value is determining a discount rate, which was discussed previously. One can select either a nominal or real discount rate, which is determined by whether it is a current or constant dollar analysis. In a current dollar analysis, the costs and benefits are not adjusted for inflation; thus, the discount rate tends to be higher. In a constant dollar analysis, the costs and benefits are adjusted to a common year for inflation; therefore, the discount rate is lower, as it does not need to account for inflation.

New technologies offer different benefits, including reduced costs or increased revenue. In order to estimate the net present value, it might be necessary to forecast any increased sales to estimate additional revenue due to adopting a new technology. It is important to also include the associated additional costs of production, but only include those costs and benefits associated with the investment. Including costs that would be incurred without the investment in the new technology will negatively skew some of the other measures discussed below.

Interpreting net present value is at times difficult. If net present value is positive, it means that the return on the investment is expected to exceed the discount rate. An anticipated follow-up question is what the rate of return is on the investment. Net present value does not reveal this information. The internal rate of return is more appropriate for answering this question. The net present value, however, can be used to determine whether an investment is economical and to rank investments.

It is important to remember that prices of some goods can change over time at rates different than general inflation. Price escalation occurs when prices increase faster than inflation, while price de-escalation occurs when prices increase slower than inflation (or decline). If an investment has a recurring cost that escalates, then the analysis will need to account for this by having higher cost values for each subsequent time period.

\section{A.5. Internal Rate of Return}

Internal rate of return is a widely-used metric for evaluating investments. It has been suggested that in some industries, it is the principal method used for such analyses. The internal rate of return is, essentially, the discount rate at which the net present value is zero. Thus, it is calculated by setting NPV in Equation 4 to equal zero and solving 
for $r .^{38,39}$ Due to the nature of this calculation, individuals use software or trial and error to identify the internal rate of return (i.e., select varying discount rates for Equation 4 in order to identify the value where the net present value equals zero).

One of the benefits of using the internal rate of return is that there is no need to select a discount rate. Generally, if the internal rate of return is calculated to be greater than or equal to your minimum required rate of return to make an investment (e.g., discount rate or hurdle rate), then the investment is economic.

Unfortunately, the internal rate of return has some deficiencies. The measure does not reveal the size of the investment. For instance, consider a $\$ 1$ investment opportunity that has a return of $100 \%$ after one year compared to a $\$ 10000$ investment that has a return of $30 \%$ after one year. The first opportunity has a higher rate of return while the second one has a higher dollar return. Net present value reveals this difference while the internal rate of return does not.

The internal rate of return also does not reveal the duration of the investment. It is often preferred to have a long-term investment rather than a short-term investment, all else equal, as it avoids the cost and risk of having to reinvest. After a short-term investment is completed, one has to identify the next investment, which may or may not have a high return. Another challenge occurs when a project generates immediate inflows. ${ }^{40}$ For instance, consider an investment that has an initial cost of \$1000 and generates \$1200 after the first year compared to one that immediately generates $\$ 1000$ and has a cost of $\$ 1200$ after the first year. Both have an internal rate of return of $20 \%$; however, using a $5 \%$ discount rate, the net present value of the first case is $\$ 143$ whereas the second one is $\$$-143. In this instance, the net present value is the better choice for analysis.

Another situation where the internal rate of return is not a sufficient metric can occur when net cash flows for different time periods flip signs. Consider an example provided by Ross where the initial net cash flow is $\$-100$, \$230 after the first year, and \$-132 in the third year. ${ }^{41}$ There are two internal rates of return with one being $10 \%$ and the other $20 \%{ }^{42}$ In this instance, one must use the net present value to make a sound decision. Moreover, the internal rate of return may be an intuitive metric; however, it should be used along with net present value rather than in place of it.

\footnotetext{
${ }^{38}$ Ross, Stephen, Randolph Westerfield, and Jeffrey Jaffe. Corporate Finance. New York, NY: McGrawHill, 2005. 152-153.

${ }^{39}$ Defusco, Richard, Dennis McLeavey, Jerald Pinto, and David Runkle. Quantitative Methods for Investment Analysis. Baltimore, MD: United Book Press, Inc, 2001. 44-49

${ }^{40}$ Ross, Stephen, Randolph Westerfield, and Jeffrey Jaffe. Corporate Finance. New York, NY: McGrawHill, 2005. 152-153.

${ }^{41}$ Ross, Stephen, Randolph Westerfield, and Jeffrey Jaffe. Corporate Finance. New York, NY: McGrawHill, 2005. 146-149.

${ }^{42}$ Ross, Stephen, Randolph Westerfield, and Jeffrey Jaffe. Corporate Finance. New York, NY: McGrawHill, 2005. 152-153.
} 


\section{A.6. Modified Internal Rate of Return}

The modified internal rate of return may or may not be a prominent method used for economic decision making; however, given the prominence of the internal rate of return and the many short comings of this metric, it is prudent to discuss the modified internal rate of return. This calculation assumes that cash inflows are reinvested at the rate of return equal to the discount rate. ${ }^{43,44}$ It can be represented as:

Equation 5

$$
M I R R=\sqrt[T]{\frac{\sum_{t=0}^{T}\left[I_{t}(1+r)^{T-t}\right]}{\sum_{t=0}^{T}\left[C_{t} /(1+r)^{t}\right]}}-1
$$

Where

$I_{t}=$ Total cash inflow in time period $t$

$C_{t}=$ Total cost in time period $\mathrm{t}$

$r=$ Discount rate

$t=$ Time period, which is typically measured in years

This equation is somewhat more complex than the calculation of the internal rate of return, but it avoids many of the downfalls associated with it. As previously mentioned, it is assumed that cash inflows are reinvested, which is why cash inflow $I_{t}$ is multiplied by $(1+r)^{T-t}$. The cost $C_{t}$ in the denominator is discounted in a similar fashion to net present value. Moreover, it is the future value of all net incomes divided by the present value of all net costs. The $T$ root of this value, less one, is equal to the modified internal rate of return.

\section{A.7. Payback Period and Discounted Payback Period}

Payback period is the time required to recoup the investment without discounting any cash flows. ${ }^{45}$ For example, consider an investment that has an initial cost of $\$ 25000$ with a net cash inflow of $\$ 10000$ after one year, \$15 000 after two years, and $\$ 12000$ after three years. The payback period is two years, as the sum of $\$ 10000$ and $\$ 15000$ equals the initial investment of $\$ 25000$. The discounted payback period makes the same estimation except the cash flows are discounted. ${ }^{46}$ Using the previously mentioned example along with a $10 \%$ discount rate, the payback period would be 3 years or less depending on when the cash flows are received during the year.

\footnotetext{
${ }^{43}$ Lin, Steven. "The Modified Internal Rate of Return and Investment Criterion.” The Engineering Economist. 1976. 21(4) 237-247.

44

${ }^{45}$ Ross, Stephen, Randolph Westerfield, and Jeffrey Jaffe. Corporate Finance. New York, NY: McGrawHill, 2005. 146-149.

${ }^{46}$ Ross, Stephen, Randolph Westerfield, and Jeffrey Jaffe. Corporate Finance. New York, NY: McGrawHill, 2005. 146-149.
} 
Payback period and the discounted payback period are often used for small investment decisions. For example, replacing a conference room's lights with energy efficient bulbs or tuning up a vehicle to save fuel. It is a quick method; however, it has a number of significant drawbacks with one being that it does not consider any future cash flows beyond the payback period. For large investments, this method should be considered a supplement to net present value.

\section{A.8. Benefit Cost Ratio}

Benefit cost ratio is the present value benefits divided by present value costs. One issue to consider is which items to include as costs. In some cases, investors might include only the initial investment as the cost. Alternatives should be compared over the same study period. A larger benefit cost ratio represents a more economic investment.

\section{A.9. Real Options and Decision Trees}

As discussed previously, net present value is considered a superior method over other approaches; however, this method does not consider the possibility of adjusting an investment after it has been initiated. A survey presented by Block indicates that $14 \%$ of Fortune 1000 companies used real options in their economic evaluations. ${ }^{47}$ Adjusting for decisions, known as real options, can provide additional value to a project. ${ }^{48}$ For instance, if a pilot or prototype product is successful, then there is the option to expand. There is also the option to abandon it in the case that it is not successful. Another example can be found in comparing two projects with the same net present value. Consider a project that commits to a technology that cannot be changed for many years compared to one with the same net present value, but there is no commitment to any particular technology. The second project is preferred over the first, as it allows for options. Moreover, real options suggests that the total value of a project is the net present value plus the value of options:

Equation 6

$$
T P V=N P V+V O
$$

Where

$T P V=$ Total project value

$N P V=$ Net present value from Equation 3 and Equation 4

$V O=$ Value of options

A great deal of the literature on real options focuses on well-defined financial options, which do not always transfer well into project investment. ${ }^{49}$ Options pricing theory is an

\footnotetext{
${ }^{47}$ Block, Stanley. “Are Real Options; Actually Used in the Real World?” The Engineering Economist. 2007 52(3) 255-267.

${ }^{48}$ Ross, Stephen, Randolph Westerfield, and Jeffrey Jaffe. Corporate Finance. New York, NY: McGrawHill, 2005. 223.

${ }^{49}$ Van Putten, Alexander and Ian MacMillan. "Making Real Options Really Work.” Harvard Business Review. December 2004. https://hbr.org/2004/12/making-real-options-really-work
} 
advanced topic, which is not completely covered in this document. For more information, one might consult Copeland and Antikarov or Brealey and Meyers. ${ }^{50,51}$

Although real options pricing is not fully discussed here, it can be described in a decision tree. There are, typically, three types of nodes in a decision tree:

Decision nodes represented by squares,

Chance nodes represented by circles, and

End nodes represented by triangles

An example is provided in Figure A.1, which presents an investment with an initial cost of \$15 million. It has a probability of 0.8 that it results in \$5 million cash inflow after one year and has the option to expand at a cost of $\$ 2$ million, resulting in an additional $\$ 30$ million cash inflow in after two years. Alternatively, there is a 0.2 probability of a cash inflow of $\$ 1$ million with the option to terminate the project at a cost of $\$ 1$ million, resulting in an additional cash inflow of \$6 million in year two. This investment has four possible net present values, as seen in Figure A.1. Since an investor would choose the highest net present value, we can eliminate those options that would not be chosen (i.e.,

the second and fourth net present values). We can then calculate the expected net present value by calculating the net present value for the branch with the probability of 0.8 which is

$$
\frac{\$ 5 \text { million }}{1.07}-\frac{\$ 2 \text { million }}{1.07^{2}}+\frac{\$ 30 \text { million }}{1.07^{2}}=\$ 29.0 \text { million }
$$

We can then calculate the expected net present value for the branch with the probability of 0.2 , which is

$$
\frac{\$ 1 \text { million }}{1.07}-\frac{\$ 1 \text { million }}{1.07^{2}}+\frac{\$ 6 \text { million }}{1.07^{2}}=\$ 5.2 \text { million }
$$

Finally, we can multiply these by their respective probabilities and add the initial cost:

$$
0.8 * \$ 29.0 \text { million }+0.2 * \$ 5.2 \text { million }-\$ 15 \text { million }=\$ 9.3 \text { million }
$$

The expected value of the investment without the options (i.e., no option to expand and no option to terminate) is $-\$ 1.5$ million; thus, the options add $\$ 10.7$ million to the net present value of the investment (i.e., the difference between $\$ 9.3$ million and $-\$ 1.5$ million before rounding).

\footnotetext{
${ }^{50}$ Brealey, Richard and Stewart Myers. Principles of Corporate Finance. $6^{\text {th }}$ ed. New York, NY: McGrawHill, 2000. 583-666

${ }^{51}$ Copeland, Tom and Vladimir Antikarov. Real Options: A Practitioner’s Guide. United Kingdom:

Thompson Corporation, 2003.
} 
Figure A. 1: Example of a Decision Tree using a 7 \% Discount Rate

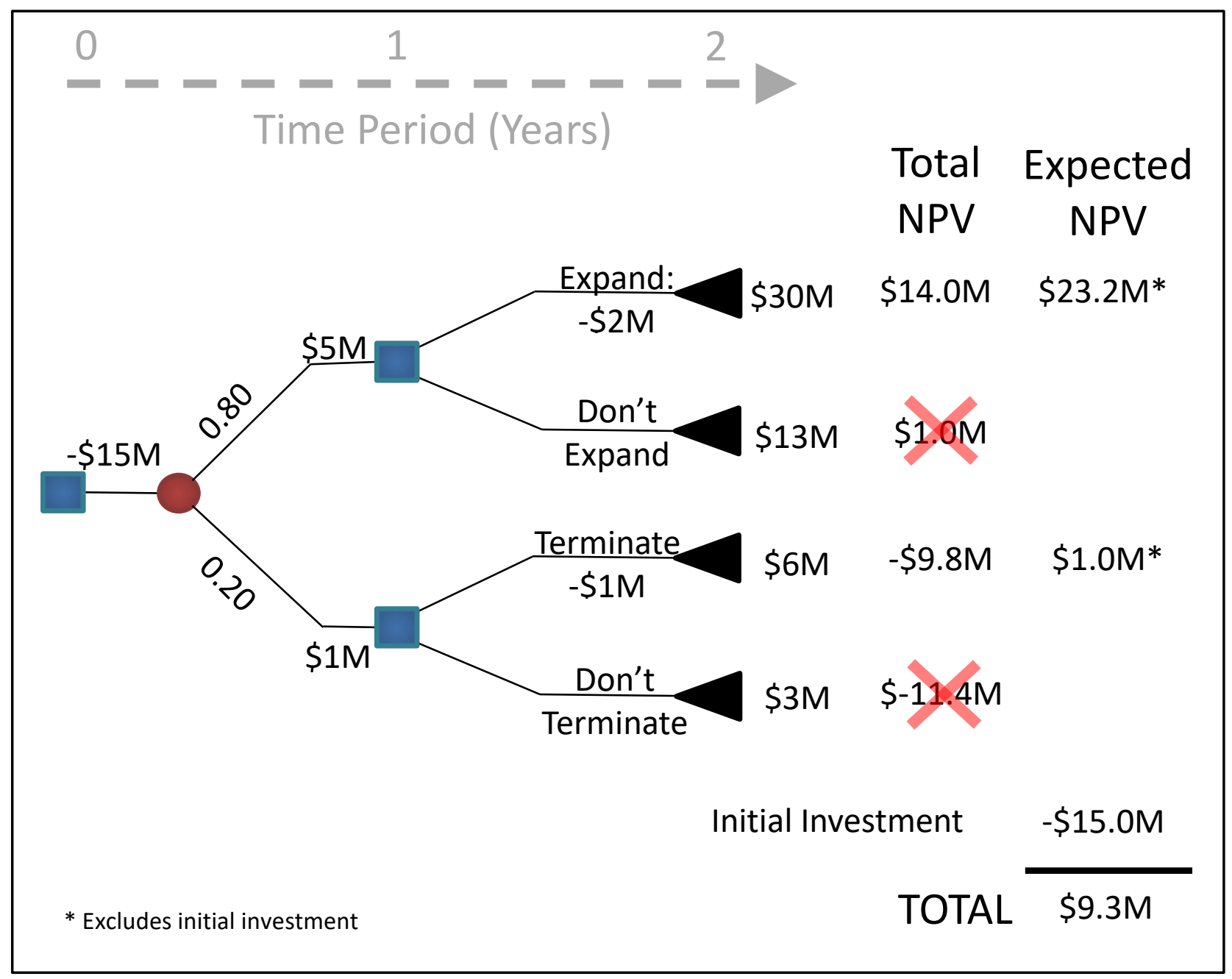

Rather than calculating the expected value, one might use a Monte Carlo analysis, as described in Appendix B. This is particularly useful in the event that there are multiple chance nodes.

\section{A.9. Adjusted Present Value}

Adjusted present value is described as the net present value plus the net present value of financing and the effects of financing. ${ }^{52}$ This includes subsidies to debt, cost of issuing new securities, cost of financial distress, or other costs/benefits of financing. It is, generally, assumed that financing occurs solely through equity:

\section{Equation 7}

\footnotetext{
52 Brealey, Richard and Stewart Myers. Principles of Corporate Finance. $6^{\text {th }}$ ed. New York, NY: McGrawHill, 2000. 555-557.
} 


$$
A P V=N P V+E F
$$

Where

$A P V=$ Adjusted present value

$N P V=$ Net present value from Equation 3 and Equation 4

$E F=$ Effects of financing (e.g., interest on a loan)

An example of the effects of financing might include a company that, in order to invest, has to issue stock, where doing so comes with costs for underwriting, lawyers, and others involved in the transaction. 


\section{Appendix B: Supplemental Information for Dealing with Uncertainty}

In addition to the methods presented in Appendix A, one often needs to consider uncertainty in data estimates. This appendix utilizes descriptions in NIST Advanced Manufacturing Series 200-5 to discuss methods for conducting an economic assessment incorporating sensitivity analysis. ${ }^{53}$

\section{B.1. Sensitivity Analysis with Monte Carlo Techniques}

To account for uncertainty, a probabilistic sensitivity analysis can be conducted using Monte Carlo methods. This technique is based on works by McKay, Conover, and Beckman $^{54}$ and by Harris ${ }^{55}$ that involves a method of model sampling. It can be implemented using various software packages such as the Crystal Ball software product ${ }^{56}$ or the Cost Effectiveness Tool provided by NIST.

Specification involves defining which variables are to be simulated, the distribution of each of these variables, and the number of iterations performed. The software then randomly samples from the probabilities for each input variable of interest. Three common distributions that are used include triangular, normal, and uniform. To illustrate, consider a situation where a firm has to purchase 100 ball bearings at $\$ 10$ each; however, the price can vary plus or minus $\$ 2$. In order to address this situation, one can use a Monte Carlo analysis where the price is varied using a triangular distribution with $\$ 12$ being the maximum, $\$ 8$ being the minimum, and $\$ 10$ being the most likely. Moreover, the anticipated results should have a low value of approximately $\$ 800$ (i.e., 100 ball bearings at $\$ 8$ each) and a high value of approximately $\$ 1200$ (i.e., 100 ball bearings at $\$ 12$ each). The triangular distribution would make it so the $\$ 8$ price and $\$ 12$ price have lower likelihoods.

For a Monte Carlo analysis, one also must select the number of iterations that the simulation will run. Each iteration is similar to rolling a pair of dice, albeit, with the probabilities having been altered. In this case, the dice determine the price of the bearings. The number of iterations is the number of times this simulation is calculated. For this example, ten thousand iterations were selected and a simulation was ran using Oracle's Crystal Ball software. The frequency graph shown in Figure B.1 shows the number of times each value was created. Since a triangular distribution was selected, the far left and far right values are less likely to be selected while the most likely value is in the middle at approximately $\$ 1000$ (i.e., 100 bearings at $\$ 10$ each). The sum of all the bars in the graph is a probability of 1.0 with a total frequency of 10000 . Instead of a

\footnotetext{
${ }^{53}$ Thomas, Douglas S. Investment Analysis Methods: A Practitioners Guide to Understanding the Basic Principles for Investment Decisions in Manufacturing. October 2017. https://doi.org/10.6028/NIST.AMS.200-5

${ }^{54}$ McKay, M. C., Conover, W. H., and Beckman, R.J. "A Comparison of Three Methods for Selecting Values of Input Variables in the Analysis of Output from a Computer Code,” Technometrics 21 (1979): 239-245.

${ }^{55}$ Harris, C. M. Issues in Sensitivity and Statistical Analysis of Large-Scale, Computer-Based Models, NBS GCR 84-466, Gaithersburg, MD: National Bureau of Standards, 1984.

${ }^{56}$ Oracle. Crystal Ball, Crystal Ball 11.1.2.3 User Manual. Denver, CO: Decisioneering, Inc, 2013.
} 
triangular distribution, a uniform distribution could have been selected where each value between $\$ 8$ and $\$ 12$ has an equal chance of being selected in each iteration. The results from such a distribution are shown in Figure B.2.

The benefit of Monte Carlo analysis is in the situation where there are many variables that can fluctuate (e.g., price of energy, materials, and labor). Instead of having just one price fluctuating, maybe a dozen prices fluctuate.

Figure B. 1: Frequency Graph of the Total Cost for Ball Bearing Example using a Triangular Distribution
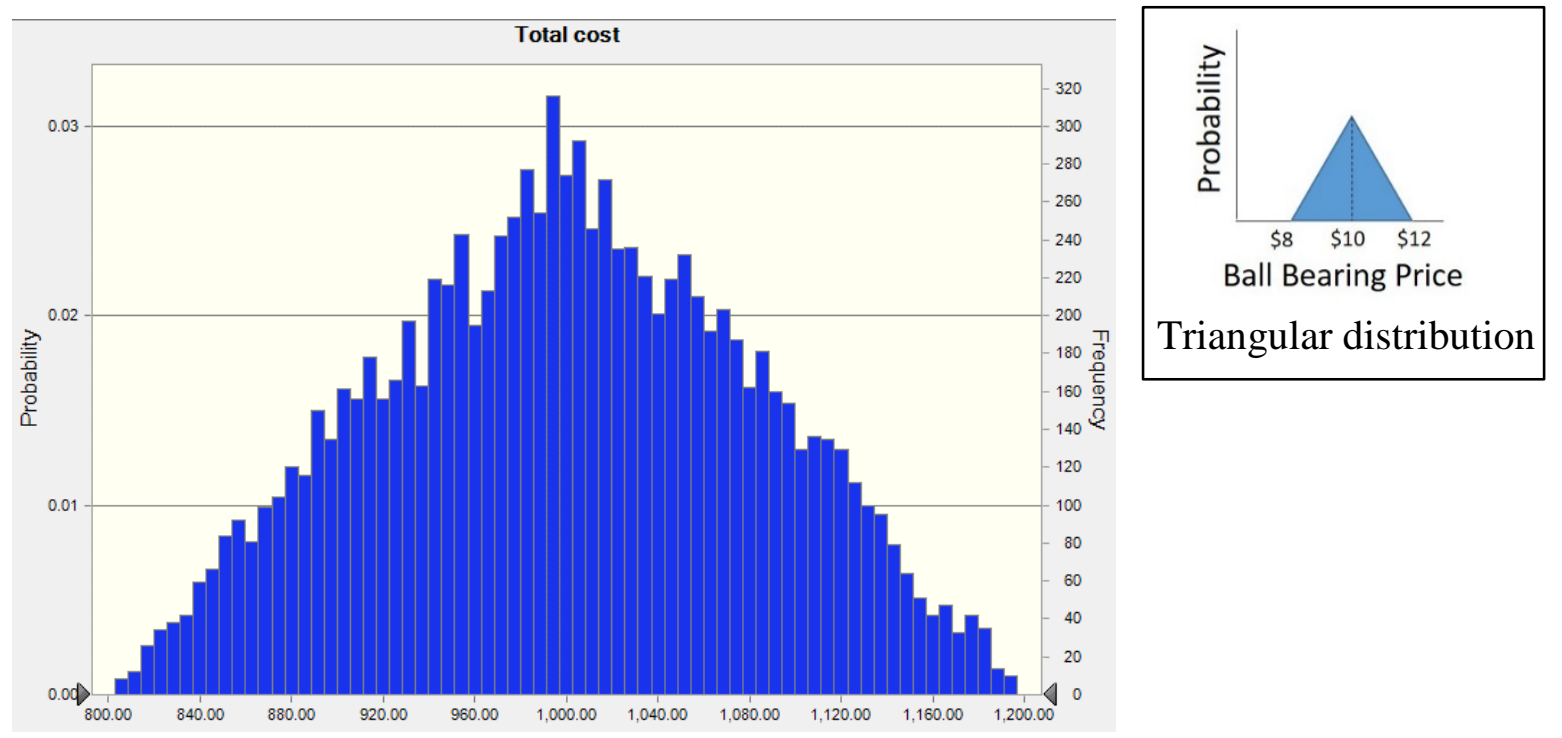

Figure B. 2: Frequency Graph of the Total Cost for Ball Bearing Example using a Uniform Distribution
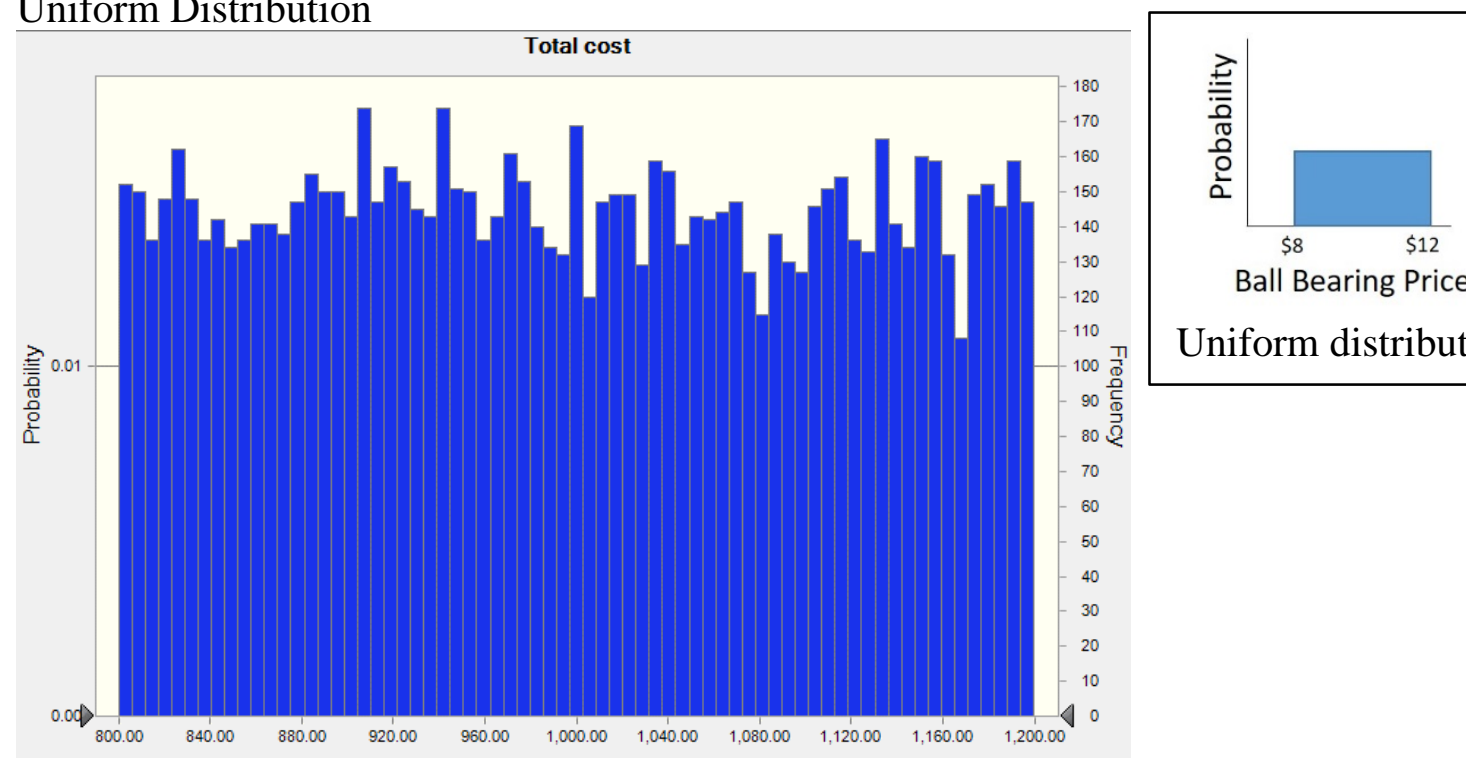

Ball Bearing Price

Uniform distribution 


\section{Appendix C: Cost Categorization}

Systematic cost categorization is needed to facilitate identifying high cost areas in manufacturing. This appendix utilizes descriptions in NIST Advanced Manufacturing Series 200-5 to discuss methods for categorizing costs. ${ }^{57}$

\section{C.1 Cost Categorization}

One challenge that is frequently faced in investment analyses is the standardization of data categories. A best practice is to use standardized costs. It aids in tracking costs throughout an industry and supply chain. Industry and occupation classification systems can be useful as a basis for categorizing costs. Two major classification systems, the North American Industry Classification System (NAICS) and the Standard Occupational Classification system (SOC), are discussed below. These systems provide a standard for tracking costs across firms and supply chains. Additionally, using these systems makes it feasible to utilize industry level data when necessary, as it is often collected in these formats. Also discussed below is a categorization of processes, which does not have a format that is as widely recognized as the NAICS or SOC systems.

\section{C.2 Categorization of Services and Commodities}

Domestic data tends to be in the North American Industry Classification System (NAICS). It is the standard used by federal statistical agencies classifying business establishments in the United States. NAICS was jointly developed by the U.S. Economic Classification Policy Committee, Statistics Canada, and Mexico's Instituto Nacional de Estadística y Geografía and was adopted in 1997. ${ }^{58}$ NAICS has several major categories each with subcategories. Historic data and some organizations continue to use the predecessor of NAICS, which is the Standard Industrial Classification system (SIC). NAICS codes are categorized at varying levels of detail. Table C.1 presents the lowest level of detail, which is the two-digit NAICS. There are 20 categories. Additional detail is added by adding additional digits; thus, three digits provides more detail than the two digit and the four digit provides more detail than the three digit. The maximum is six digits, as illustrated for automobile manufacturing (NAICS 336111) and light truck and utility manufacturing (NAICS 336112). Sometimes a two, three, four, or five-digit code is followed by zeros, which do not represent categories. They are null or place holders. For example, the code 336000 represents NAICS 336.

\section{C.3 Labor Categorization}

Federal statistical agencies classify workers into occupational categories for collecting and distributing data on employees using the Standard Occupational Classification

\footnotetext{
57 Thomas, Douglas S. Investment Analysis Methods: A Practitioners Guide to Understanding the Basic Principles for Investment Decisions in Manufacturing. October 2017. https://doi.org/10.6028/NIST.AMS.200-5

${ }^{58}$ US Census Bureau. North American Industry Classification System.

$<$ http://www.census.gov/eos/www/naics/>
} 
system (SOC). The 2010 version has 840 occupations. These are categorized into 23 major groups. Occupations with similar job duties, skills, categorized into 461 broad occupations, which are categorized into 97 minor groups, education, and/or training are grouped together. Similar to the NAICS codes, additional digits represent additional detail up to a maximum of six digits, as illustrated for SOC 514011 and SOC 514012 in Table C.2, which presents the 23 major groups. The SOC classifies all occupations in which work is performed for pay or profit. It was first published in 1980, but was rarely utilized at that time. In 2000, it was revised and then again revised in 2010. The Bureau of Labor Statistics now publishes occupation data based on this system.

\section{C.3 Process Categorization}

Thompson (2015) provides a convenient list of manufacturing processes (see Table C.3); however, the Thompson's intention is not to provide a method of categorization. ${ }^{59}$

\begin{tabular}{|c|c|}
\hline Sector & Description \\
\hline 11 & Agriculture, Forestry, Fishing and Hunting \\
\hline 21 & Mining, Quarrying, and Oil and Gas Extraction \\
\hline 22 & Utilities \\
\hline 23 & Construction \\
\hline 31-33 & Manufacturing \\
\hline 336 & Transportation Equipment Manufacturing \\
\hline 3361 & Motor Vehicle Manufacturing \\
\hline 33611 & Automobile and Light Duty Motor Vehicle Manufacturing \\
\hline 336111 & Automobile Manufacturing \\
\hline 336112 & Light Truck and Utility Manufacturing \\
\hline 42 & Wholesale Trade \\
\hline 44-45 & Retail Trade \\
\hline $48-49$ & Transportation and Warehousing \\
\hline 51 & Information \\
\hline 52 & Finance and Insurance \\
\hline 53 & Real Estate and Rental and Leasing \\
\hline 54 & Professional, Scientific, and Technical Services \\
\hline 55 & Management of Companies and Enterprises \\
\hline 56 & Administrative and Support and Waste Management and Remediation Services \\
\hline 61 & Educational Services \\
\hline 62 & Health Care and Social Assistance \\
\hline 71 & Arts, Entertainment, and Recreation \\
\hline 72 & Accommodation and Food Services \\
\hline 81 & Other Services (except Public Administration) \\
\hline 92 & Public Administration \\
\hline
\end{tabular}

\footnotetext{
59 Thompson, Rob. Manufacturing Processes for Design Professionals. New York, NY: Thames \& Hudson,
} 2015. 
Table C. 2: Standard Occupational Classification System, Two Digit Codes

\begin{tabular}{|c|c|}
\hline Occupation Code & Occupation Name \\
\hline 11 & Management Occupations \\
\hline 13 & Business and Financial Operations Occupations \\
\hline 15 & Computer and Mathematical Occupations \\
\hline 17 & Architecture and Engineering Occupations \\
\hline 19 & Life, Physical, and Social Science Occupations \\
\hline 21 & Community and Social Service Occupations \\
\hline 23 & Legal Occupations \\
\hline 25 & Education, Training, and Library Occupations \\
\hline 27 & Arts, Design, Entertainment, Sports, and Media Occupations \\
\hline 29 & Healthcare Practitioners and Technical Occupations \\
\hline 31 & Healthcare Support Occupations \\
\hline 33 & Protective Service Occupations \\
\hline 35 & Food Preparation and Serving Related Occupations \\
\hline 37 & Building and Grounds Cleaning and Maintenance Occupations \\
\hline 39 & Personal Care and Service Occupations \\
\hline 41 & Sales and Related Occupations \\
\hline 43 & Office and Administrative Support Occupations \\
\hline 45 & Farming, Fishing, and Forestry Occupations \\
\hline 47 & Construction and Extraction Occupations \\
\hline 49 & Installation, Maintenance, and Repair Occupations \\
\hline 51 & Production Occupations \\
\hline 514 & Metal Workers and Plastic Workers \\
\hline 5140 & Metal Workers and Plastic Workers \\
\hline 51401 & Computer Control Programmers and Operators \\
\hline 514011 & Computer-Controlled Machine Tool Operators, Metal and Plastic \\
\hline 514012 & Computer Numerically Controlled Machine Tool Programmers, Metal and Plastic \\
\hline 53 & Transportation and Material Moving Occupations \\
\hline 55 & Military Specific Occupations \\
\hline
\end{tabular}

Manufacturing processes do not have a standard system of classification that is as widely known as NAICS or the SOC. There are, however, a number of classification schemes, as seen in Table C.4 which is taken from Mani et al. (2013). Each of the schemes shown have advantages and a different basis for classification.

The National Research Council (NRC), for example, has a committee on unit manufacturing process research that identifies unit processes as a basis for classification. ${ }^{60}$ According to NRC, there are five physical process categories:

1. Mass-change processes, which remove or add material by mechanical, electrical, or chemical means (included are the traditional processes of machining, grinding,

\footnotetext{
${ }^{60}$ Unit Manufacturing Process Research Committee, National Research Council. Unit Manufacturing Processes: Issues and Opportunities in Research. Washington DC: The National Academic Press, 1995.
} 
Table C. 3: Manufacturing Process Categories
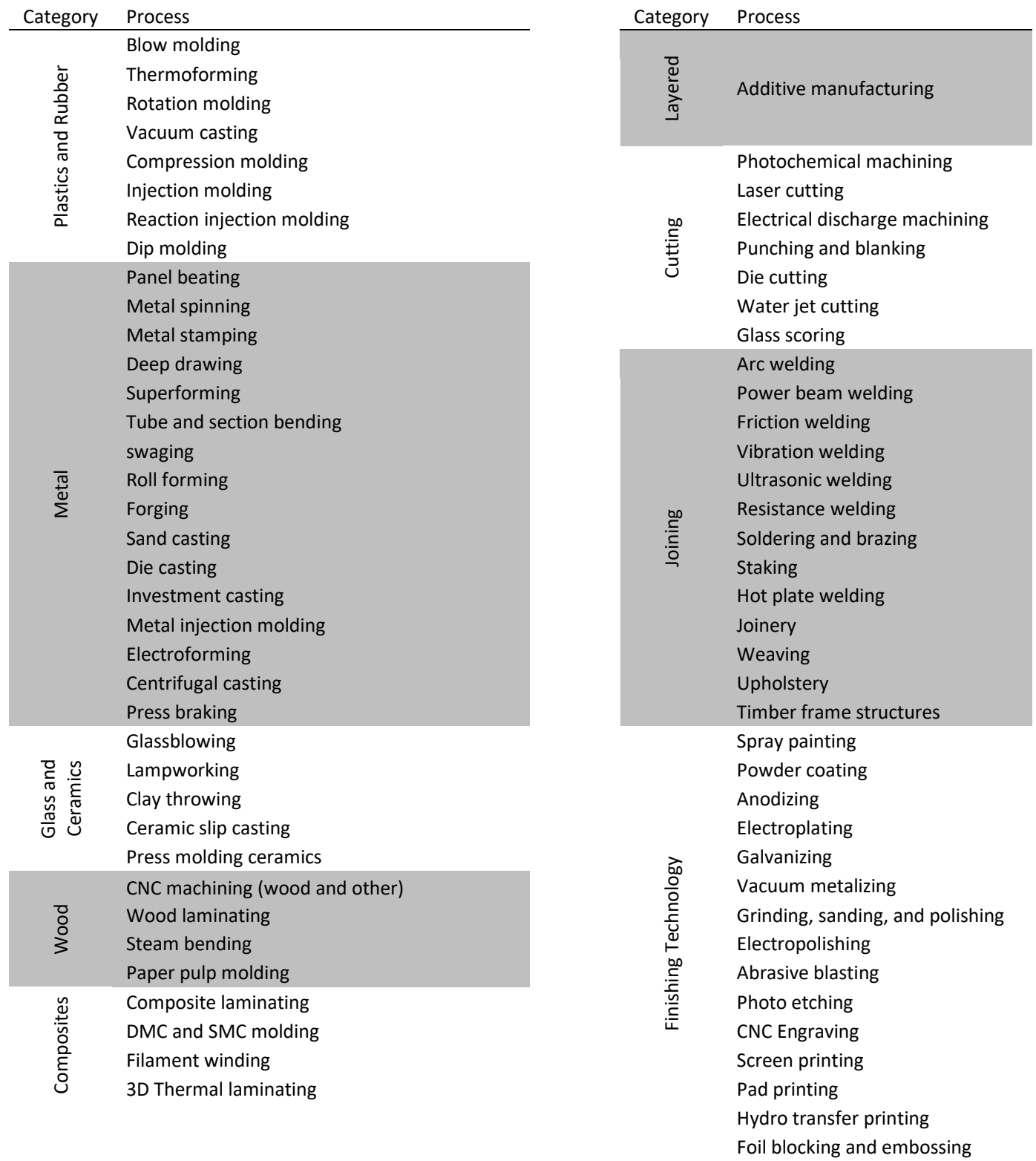

Source: Thompson, Rob. Manufacturing Processes for Design Professionals. New York, NY: Thames \& Hudson, 2015. 
Table C. 4: Selection of Manufacturing Process Classifications

\begin{tabular}{|c|c|c|c|c|c|c|}
\hline & \multicolumn{6}{|c|}{ Source } \\
\hline & NRC & Todd et al & DIN 8580 & Paul DeGarmo & Ashby & Mil \\
\hline 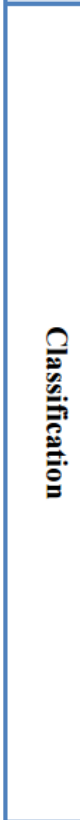 & $\begin{array}{l}\text { Five families of } \\
\text { physical } \\
\text { processes } \\
\text { - Mass-change } \\
\text { processes } \\
\text { - Phase-change } \\
\text { processes } \\
\text { - Structure- } \\
\text { change } \\
\text { processes } \\
\text { - Deformation } \\
\text { processes } \\
\text { - Consolidation } \\
\text { processes }\end{array}$ & $\begin{array}{l}\text { Six families of } \\
\text { Shaping } \\
\text { processes } \\
\text { - Mass } \\
\text { Reducing } \\
\text { - Thermal Mass } \\
\text { Reducing } \\
\text { - Chemical } \\
\text { Mass } \\
\text { Reducing } \\
\text { - Mass } \\
\text { Conserving } \\
\text { - Consolidation } \\
\text { - Joining } \\
\text { Four families of } \\
\text { Non-shaping } \\
\text { processes } \\
\text { - Hardening } \\
\text { - Softening } \\
\text { - Surface } \\
\text { Preparation } \\
\text { - Surface } \\
\text { Coatings }\end{array}$ & $\begin{array}{l}\text { Six groups of } \\
\text { manufacturing } \\
\text { processes } \\
\text { - Original } \\
\text { Forming } \\
\text { - Transforming } \\
\text { - Separating } \\
\text { - Joining } \\
\text { - Coating and } \\
\text { Finishing } \\
\text { - Change of } \\
\text { Material } \\
\text { Properties }\end{array}$ & $\begin{array}{l}\text { Seven types are } \\
\text { identified } \\
\text { - Casting or } \\
\text { Molding } \\
\text { - Forming or } \\
\text { Shearing } \\
\text { - Machining } \\
\text { (material } \\
\text { removal) } \\
\text { - Heat Treating } \\
\text { - Finishing } \\
\text { - Assembly } \\
\text { - Inspection }\end{array}$ & $\begin{array}{l}\text { Four groups of } \\
\text { manufacturing } \\
\text { processes } \\
\text { - Primary } \\
\text { shaping } \\
\text { processes: } \\
\text { - Secondary } \\
\text { processes: } \\
\text { - Joining } \\
\text { - Finishing }\end{array}$ & $\begin{array}{l}\text { Manufacturing } \\
\text { Management } \\
\text { Taxonomy } \\
\text { - Product } \\
\text { Design } \\
\text { - Process } \\
\text { Design\& } \\
\text { Control } \\
\text { - Supply Chain } \\
\text { Management }\end{array}$ \\
\hline 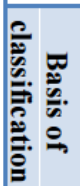 & Physical change & $\begin{array}{l}\text { Shaping/Non- } \\
\text { shaping }\end{array}$ & $\begin{array}{l}\text { Forming/ } \\
\text { Transforming/ } \\
\text { Material } \\
\text { Property }\end{array}$ & $\begin{array}{l}\text { Casting/Forming/ } \\
\text { Material Property }\end{array}$ & $\begin{array}{l}\text { Primary/ } \\
\text { Secondary }\end{array}$ & $\begin{array}{l}\text { Manufacturing } \\
\text { Management }\end{array}$ \\
\hline 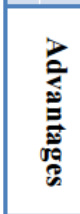 & Science-based & Ease of use & $\begin{array}{l}\text { Being used in } \\
\text { CO2PE! effort } \\
\text { for determining } \\
\text { LCI of } \\
\text { Manufacturing } \\
\text { Processes }\end{array}$ & Simple & Simple & Management \\
\hline
\end{tabular}

Source: Mani, Mahesh, Jatinder Madan, Jae Hyun Lee, Kevin W. Lyons, and Satyandra K. Gupta. 2013. Review on Sustainability Characterization for Manufacturing Processes. NISTIR 7913. http://nvlpubs.nist.gov/nistpubs/ir/2013/NIST.IR.7913.pdf

and plating, as well as such nontraditional processes as electrodischarge and electrochemical machining)

2. Phase-change processes, which produce a solid part from material originally in the liquid or vapor phase (typical examples are the casting of metals, the manufacture of composites by infiltration, and injection molding of polymers)

3. Structure-change processes, which alter the microstructure of a workpiece, either throughout its bulk or in a localized area such as its surface (heat treatment and surface hardening are typical processes within this family; the family also encompasses phase changes in the solid state, such as precipitation hardening)

4. Deformation processes, which alter the shape of a solid workpiece without changing its mass or composition (classical bulk-forming metalworking processes of rolling and forging are in this category, as are sheet-forming processes such as deep drawing and ironing) 
5. Consolidation processes, which combine materials such as particles, filaments, or solid sections to form a solid part or component (powder metallurgy, ceramic molding, and polymer-matrix composite pressing are examples, as are joining processes, such as welding and brazing).

A more recognized taxonomy of processes is presented by Todd et al. (1994). ${ }^{61}$ Table C.5 presents a manufacturing process classification based on their taxonomy. For this report, a process code was developed similar to that of the NAICS and SOC and applied to their taxonomy. It is a six-digit code where additional detail is added by adding additional digits; thus, three digits provides more detail than the two digit and the four digit provides more detail than the three digit. Unfortunately, the taxonomy presented by Todd et al is over 20 years old; therefore, there is, likely, a need to incorporate more recent developments for this taxonomy to be completely relevant.

${ }^{61}$ Todd, Robert H., Dell K. Allen, and Leo Alting. Manufacturing Processes Reference Guide. New York, NY: Industrial Press, Inc, 1994. xiii-xxiv. 
Table C. 5: Manufacturing Process Classification (Based on Todd et al. 1994)

\begin{tabular}{|c|c|c|c|}
\hline Process Code & Description & Process Code & Description \\
\hline 100000 & Shaping & 112330 & Ion Beam Cutting \\
\hline 110000 & Mass Reducing & 113000 & Chemical Reducing \\
\hline 111000 & Mechanical Reducing & 113100 & Chemical Milling \\
\hline 111100 & Reducing (chips) & 113110 & Immersion Chemical Milling \\
\hline 111110 & Single-Point Cutting & 113120 & Spray Chemical Milling \\
\hline 111111 & Turning/Facing & 113200 & Electrochemical Milling \\
\hline 111112 & Boring & 113210 & Cavity-Type \\
\hline 111113 & Shaping/Planing & 113220 & Grinder-Type \\
\hline 111114 & Parting/Grooving & 113300 & Photochemical Milling \\
\hline 111115 & Threading (SP) & 113310 & Photo Etching \\
\hline 111120 & Multipoint Cutting & 113320 & Photo Milling \\
\hline 111121 & Drilling & 120000 & Mass Conserving \\
\hline 111122 & Reaming & 121000 & Consolidation \\
\hline 111123 & Milling/Routing & 121100 & Casting - Nonreusable \\
\hline 111124 & Broaching & 121110 & Ceramic Mold Casting \\
\hline 111125 & Threading (MP) & 121111 & Investment Casting \\
\hline 111126 & Filing & 121112 & Plaster Mold Casting \\
\hline 111127 & Sawing & 121120 & Sand Mold Casting \\
\hline 111128 & Gear Cutting & 121121 & Sand Casting \\
\hline 111130 & Abrasive machining & 121122 & Shell Mold Casting \\
\hline 111131 & Grinding & 121123 & No-Bake Mold Casting \\
\hline 111132 & Honing & 121124 & Full-Mold Casting \\
\hline 111133 & Lapping & 121200 & Casting - Reusable Mold \\
\hline 111134 & Superfinishing & 121210 & Die Casting \\
\hline 111135 & Ultrasonic Machining & 121220 & Permanent Mold Casting \\
\hline 111136 & Jet Machining & 121230 & Flexible Mold Casting \\
\hline 111200 & Seperating (shear) & 121240 & Continuous Casting \\
\hline 111210 & Shearing & 121300 & Molding \\
\hline 111211 & Squaring & 121310 & Ceramic Molding \\
\hline 111212 & Slitting & 121311 & Wet Forming \\
\hline 111213 & Rotary Shearing & 121312 & Dry Pressing \\
\hline 111214 & Nibbling & 121320 & Polymer Molding \\
\hline 111220 & Blanking & 121321 & Injection Molding \\
\hline 111221 & Conventional Blanking & 121322 & Blow Molding \\
\hline 111222 & Steel-Rule-Die Blanking & 121323 & Transfer Molding \\
\hline 111223 & Fine Blanking & 121324 & Compression Molding \\
\hline 111224 & Shaving/Trimming & 121325 & Extrusion Molding \\
\hline 111225 & Dinking & 121326 & Thermoform Molding \\
\hline 111230 & Piercing & 121327 & Rotational Molding \\
\hline 111231 & Punching & 121400 & Compacting \\
\hline 111232 & Perforating & 121410 & Continuous Compacting \\
\hline 111233 & Lancing & 121411 & Powder Material Extrusion \\
\hline 111234 & Notching & 121412 & Powder Material Rolling \\
\hline 112000 & Thermal Reducing & 121420 & Noncontinuous Compacting \\
\hline 112100 & Torch Cutting & 121500 & Deposition \\
\hline 112110 & Air Arc Cutting & 121510 & Electroforming \\
\hline 112120 & Gas Cutting & 121600 & Laminating \\
\hline 112130 & Plasma Arc Cutting & 121610 & Filament Winding \\
\hline 112200 & Electrical Discharge Machining (EDM) & 121620 & Sheet Laminating \\
\hline 112210 & Cavity-Type & 121630 & Bulk Laminating \\
\hline 112220 & Grinding & 121631 & Spray Lay-up \\
\hline 112230 & Sawing & 121632 & Hand Lay-up \\
\hline 112300 & High Energy Beam Machining & 121640 & Pultrusion \\
\hline 112310 & Electron Beam Cutting & 122000 & Total Deformation \\
\hline 112320 & Laser Beam Cutting & 122100 & Forging \\
\hline
\end{tabular}




\begin{tabular}{|c|c|c|c|}
\hline Process Code & Description & Process Code & Description \\
\hline 122110 & Hot Forging & 131200 & Inertial Friction Welding \\
\hline 122111 & Hammer Forging & 131300 & Ultrasonci Welding \\
\hline 122112 & Drop Forging & 131400 & Explosive Welding \\
\hline 122113 & Press Forging & 132000 & Thermal Joining \\
\hline 122114 & Upset Forging & 132100 & Thermal Welding \\
\hline 122115 & Roll Forging & 132110 & Electric Arc Welding \\
\hline 122120 & Cold Forging & 132111 & Shielded Metal Arc Welding \\
\hline 122200 & Extruding & 132112 & Gas Metal Arc (MIG) Welding \\
\hline 122210 & Direct Extrusion & 132113 & Gas Tungsten Arc (TIG) Welding \\
\hline 122220 & Indirect Extrusion & 132114 & Submerged Arc Welding \\
\hline 122230 & Impact Extrusion & 132115 & Carbon Arc Welding \\
\hline 122300 & Drawing & 132116 & Stud Welding \\
\hline 122310 & Wire Drawing & 132120 & Electrical Resistance Welding \\
\hline 122320 & Tube Drawing & 132121 & Spot Welding \\
\hline 122400 & Rolling & 132122 & Seam Welding \\
\hline 122410 & Sheet Rolling & 132123 & Projection Welding \\
\hline 122420 & Foil Rolling & 132124 & Butt Welding \\
\hline 122430 & Structural Rolling & 132125 & Percussion Welding \\
\hline 122440 & Pierce Rolling & 132126 & Electroslag Welding \\
\hline 122500 & Shear Spinning & 132130 & Gas/Chemical Welding \\
\hline 122600 & Coining/Sizing/Hobbing & 132131 & Combustible Gas Welding \\
\hline 122700 & Thread Forming & 132132 & Atomic Hydrogen Welding \\
\hline 122800 & Knurling & 132140 & Braze Welding \\
\hline 123000 & Local Deformation & 132141 & Gas Brazing \\
\hline 123100 & Bending & 132142 & Carbon Arc Brazing \\
\hline 123110 & Straight Angle Bending & 132150 & Diffusion Bonding \\
\hline 123120 & Corrugation Bending & 132160 & High Energy Beam Welding \\
\hline 123130 & Joggle Bending & 132161 & Electron Beam Welding \\
\hline 123140 & Curling & 132162 & Laser Beam Welding \\
\hline 123150 & Seaming & 132163 & Plasma Arc Welding \\
\hline 123160 & Tube Bending & 132200 & Brazing \\
\hline 123170 & Roll Forming & 132210 & Infrared Brazing \\
\hline 123200 & Conventional Sheeting Forming & 132220 & Resistance Brazing \\
\hline 123210 & Die Forming: Matched Die Drawing & 132230 & Torch Brazing \\
\hline 123211 & Simple Rigid Die & 132240 & Dip Brazing \\
\hline 123212 & Compound Die & 132250 & Furnace Brazing \\
\hline 123213 & Progressive Die & 132260 & Induction Brazing \\
\hline 123220 & Die Forming: Rubber Die Drawing & 132300 & Soldering \\
\hline 123221 & Guerin Process & 132310 & Friction/Ultrasonic Soldering \\
\hline 123222 & Martform Process & 132320 & Induction Soldering \\
\hline 123223 & Hydroform Process & 132330 & Infrared Soldering \\
\hline 123230 & Conventional Spinning & 132340 & Dip Soldering \\
\hline 123240 & Stretch Forming & 132350 & Iron Soldering \\
\hline 123250 & Embossing & 132360 & Resistance Soldering \\
\hline 123300 & Conventional Tube Forming & 132370 & Torch Soldering \\
\hline 123310 & Swaging & 132380 & Wave Soldering \\
\hline 123320 & Flaring & 133000 & Chemical Joining: adhesive bonding \\
\hline 123330 & Intraforming & 200000 & Nonshaping \\
\hline 123400 & High Energy Rate Forming & 210000 & Heat Treatment \\
\hline 123410 & Explosive Forming & 212000 & Annealing \\
\hline 123420 & Electromagnetic Forming & 212100 & Recovery \\
\hline 123430 & Electrohydraulic Forming & 212110 & Stress Relieving \\
\hline 130000 & Joining & 212120 & Tempering \\
\hline 131000 & Mechanical Joining & 212200 & Recrystallization \\
\hline 131100 & Cold Pressure Welding & 212210 & Full Annealing \\
\hline
\end{tabular}




\begin{tabular}{|c|c|c|c|}
\hline Process Code & Description & Process Code & Description \\
\hline 212220 & Process Annealing & 222000 & Surface Coating \\
\hline 212230 & Short-Cycle Annealing & 222100 & Mechanical Coating \\
\hline 213000 & Hardening & 222110 & Spray Coating: Pressure Transferred \\
\hline 213100 & Surface Hardening & 222111 & Air Gun Spraying \\
\hline 213110 & Carburizing & 222112 & High Pressure Airless Spray \\
\hline 213120 & Chromizing & 222120 & Spray Coating: Charged Transferred \\
\hline 213130 & Carbonitriding & 222121 & Electrostatic Coating \\
\hline 213140 & Cyaniding & 222122 & Vacuum Coating \\
\hline 213150 & Nitriding & 222130 & Dip/Flow Coating \\
\hline 213160 & Diffusion Hardening & 222131 & Cold Dip Coating \\
\hline 213170 & Flame Hardening & 222132 & Hot Dip Coating \\
\hline 213180 & Induction Hardening & 222133 & Electrocoating \\
\hline 213200 & Through Hardening & 222134 & Fluidized Bed Coating \\
\hline 213210 & Water Quench Hardening & 222135 & Curtain Coating \\
\hline 213220 & Oil Quench Hardening & 222140 & Dust Coating \\
\hline 213230 & Air Quench Hardening & 222150 & Roll Coating \\
\hline 213240 & Martempering & 222151 & Calendering \\
\hline 213250 & Austempering & 222152 & Roller Coating \\
\hline 213260 & Age Hardening & 222200 & Thermal Coating \\
\hline 214000 & Other Heat Treatment & 222210 & Flame Spraying \\
\hline 214100 & Sintering & 222211 & Combustion Flame Spraying \\
\hline 214110 & Solid-Phase Sintering & 222212 & Plasma Arc Spraying \\
\hline 214120 & Liquid-Phase Sintering & 222213 & Detonation Gun Spraying \\
\hline 214200 & Subzero Cold Treatment & 222220 & Vaporized Metal Coating \\
\hline 214300 & Firing/Glazing & 222221 & Vacuum Metallizing \\
\hline 214400 & Curing/Bonding & 222222 & Sputtering \\
\hline 220000 & Surface Finish & 222223 & Chemical Vapor-Phase Deposition \\
\hline 221000 & Surface Preparation & 222230 & Heat Tinting \\
\hline 221100 & Descaling & 222300 & Chemical Coating \\
\hline 221110 & Mechanical Descaling & 222310 & Electroplating \\
\hline 221111 & Abrasive Blasting & 222320 & Chemical Conversion \\
\hline 221112 & Belt Sanding & 222321 & Anodize \\
\hline 221113 & Shot Peening Preparation & 222322 & Alkaline Oxide \\
\hline 221114 & Wire Brushing & 222323 & Fused Nitrate \\
\hline 221115 & Grinding & 222324 & Proprietary Treatments \\
\hline 221120 & Thermal Descaling & 222325 & Phosphate \\
\hline 221121 & Flame Cleaning & 222326 & Chromate \\
\hline 221130 & Chemical Descaling & 223000 & Surface Modification \\
\hline 221131 & Chemical Pickling & 223100 & Burnishing \\
\hline 221200 & Deburring & 223200 & Peening \\
\hline 221210 & Mechanical Deburring & 223210 & Shot Peening \\
\hline 221211 & Barrel Tumbling & 223220 & Hammer Peening \\
\hline 221212 & Vibratory Finishing & 223300 & Texturing \\
\hline 221213 & Knife Deburring & 223310 & Wire Brush Finishing \\
\hline 221220 & Thermal Deburring & 223320 & Buffing/Polishing \\
\hline 221221 & Thermochemical Deburring & & \\
\hline 221230 & Chemical Deburring & & \\
\hline 221231 & Electrochemical Deburring & & \\
\hline 221300 & Degreasing & \multirow{7}{*}{\multicolumn{2}{|c|}{$\begin{array}{l}\text { Source: Todd, Robert H., Dell K. Allen, and Leo } \\
\text { Alting. Manufacturing Processes Reference Guide. } \\
\text { New York, NY: Industrial Press, Inc, 1994. xiii-xxiv. }\end{array}$}} \\
\hline 221310 & Mechanical Degreasing & & \\
\hline 221311 & Ultrasonic Degreasing & & \\
\hline 221320 & Chemical Degreasing & & \\
\hline 221321 & Vapor Degreasing & & \\
\hline 221322 & Solvent Degreasing & & \\
\hline 221323 & Alkali Degreasing & & \\
\hline
\end{tabular}




\section{Appendix D: The Analytical Hierarchy Process}

The analytic hierarchy process (AHP) is a technique developed by Saaty (1980) ${ }^{62}$ to assist in decision-making when dealing with multi-attribute criteria. It uses pairwise comparisons as the fundamental analytical tool in its decision-making process. Since its introduction, the technique has been used in a range of fields from risk assessment for petroleum transport to choosing professors at a university. Due to the complicated, multistep process that many manufacturers face when dealing with a range of issues from selecting a product to manufacture to choosing among a slew of investments in various manufacturing operations, AHP is an ideal tool for dealing with the complex decisions that manufacturers must make.

AHP can be applied to prioritization, ranking, and benchmarking situations. It can also be utilized for resource allocation and quality management decision-making. The range of possible applications of AHP means that a manufacturer can use the process for nearly all the complex decision-making choices she faces.

Although AHP can be conducted in several different ways, the core steps remain the same. First, in the case of a manufacturer, the manufacturer must identify all of the possible outcomes/choices at all levels of the decision-making process. Sometimes manufacturers face a decision-making process that is sequential in nature, while other times the decisionmaking process may require simultaneous choices. All types of decision-making are covered by AHP, but the decision-maker must identify all possible ranges of outcomes before embarking on the AHP process. If the decision-maker does not identify the full range of possible outcomes at the onset, she would need to repeat the process once the full breadth of options is known so that the process results in the best choice for the decisionmaker.

The best way to demonstrate the efficacy of AHP is by working through an example. Let us assume that a manufacturer of prefabricated homes wants to package solar panels along with the homes they are building. There are three possible solar panel vendors that our manufacturer can choose among - vendors A, B, and C. The manufacturer naturally wants to choose the "best" solar panels for its prefabricated homes. But what constitutes the "best" in these circumstances?

Let us further assume that the manufacturer already has a set of criteria on what constitutes the "best" for solar panels; namely solar panels that prevail on four different dimensions cost, aesthetics, solar cell efficiency, and resale value. Note that while some of these criteria can be quantified exactly - like the cost - others, like resale value, rely on future market conditions that can only be imprecisely known and therefore must be estimated. The fact that some criteria are exactly known and that others must be estimated does not stop the manufacturer from conducting the AHP analysis however.

\footnotetext{
${ }^{62}$ Saaty, Thomas L. The Analytic Hierarchy Process: Planning, Priority Setting, Resource Allocation. (McGraw-Hill, 1980).
} 
What is also important to note is that some of these criteria may be subdivided into $\neg$ subcriteria. For the sake of our example, we will also assume that solar cell efficiency can be further divided into two sub-criteria -- thermodynamic and quantum efficiency. Thus, two of our criteria have sub-criteria and two do not.

As Saaty (1980) developed it, AHP relies on the preferences of the person or entity making the decision. Because a manufacturer might be choosing between criteria that are measured on different dimensions - like cost and efficiency - the AHP calculation is invaluable in creating a standard metric that enables the comparison of alternatives.

AHP requires us to use pairwise comparisons in making our ultimate decision. In fact, AHP can be thought of as the aggregation of sets of pairwise comparisons. AHP calculations can be accomplished by any number of software packages, but we will walk through the intuition driving those calculations here.

In making the pairwise comparisons, AHP requires that the decision-maker quantifies their preferences on a numerical scale. The widespread convention with AHP is to use a ninepoint scale that was first published in Expert Choice User's Guide, Decision Support Software, Inc., Pittsburgh, PA, 1993 and which is reprinted on page 275 of the ASTM Standards on Building Economics, $7^{\text {th }}$ Edition. That table is reproduced below (see Table D.1).

Table D. 1: AHP Numerical Scale

\begin{tabular}{|c|c|c|}
\hline Intensity of Importance & Definition & Explanation \\
\hline 1 & Equal Importance & $\begin{array}{c}\text { Two activities contribute } \\
\text { equally to objective }\end{array}$ \\
\hline 3 & Moderate Importance & $\begin{array}{l}\text { Slightly favor one activity } \\
\text { over another }\end{array}$ \\
\hline 5 & Essential Importance & $\begin{array}{c}\text { Strongly favor one activity } \\
\text { over another }\end{array}$ \\
\hline 7 & Very Strong Importance & $\begin{array}{l}\text { Very strongly favor one } \\
\text { activity over another }\end{array}$ \\
\hline 9 & Extreme Importance & $\begin{array}{c}\text { Favor one activity over } \\
\text { another as strongly as } \\
\text { possible }\end{array}$ \\
\hline $2,4,6,8$ & Intermediate Values & $\begin{array}{l}\text { Compromise between two } \\
\text { of the defined values }\end{array}$ \\
\hline
\end{tabular}

From this table, we see that the importance of an alternative goes up as one makes the journey up the scale, with nine reflecting a value of "extreme importance." The even numbers in this scheme represent the "intermediate values" between the main AHP intensities. It is this table that is used when developing weights for the preferences. As will be explained below, some inconsistency in the preference weightings is tolerable in AHP. 
Now we need to do pairwise comparisons between each of the alternatives, stating which of any two options is the preferred criteria and the intensity of that preference. The decision-maker can choose whatever preferences they want and indicate those efficiencies, as long as relative consistency is not violated. Consistency here is obtained when the priorities are unique and the preference order of the pairwise comparison matrices is also maintained. AHP allows for some inconsistencies because some cardinal inconsistency is expected when dealing with people ranking choices. However, a good software tool will prevent too much inconsistency from showing up in the AHP model. Saaty crated a measure known as the consistency index (CI) that allows the user to check the consistency of their own preference as part of the larger AHP process. The CI formula is expressed as:

$$
C I=(\lambda \max -n) /(n-1)
$$

where $\lambda$ max is the Principal Eigenvalue and $n$ is the dimension of the matrix

The steps for calculating the CI are easy to follow. First one must arrange all of the pairwise comparisons into matrices. Then each column of the pair wise comparison matrix must be multiplied by the corresponding weight. Then we must divide the sum of the row entries by the corresponding weight. Afterwards we average all of the values derived from the previous step. It is this average which is $\lambda$ max. Knowing that $\mathrm{n}$ is the dimension of the matrix, we can now calculate the CI.

The standard practice for AHP is to proceed with the analysis when the CR $=0.1$ or a value below that. This allows for some inconsistency in the preferences and means that some violations of transitivity can be allowed.

A good AHP software program will calculate these consistency ratios and not let the decision-maker proceed if even one of these consistency ratios is violated. Below is an example that has been generated where none of the consistency ratios has been violated (see Table D.2).

Table D. 2: Example of AHP Pairwise Comparisons for Solar Panels

\begin{tabular}{|c|c|c|c|}
\hline & Aesthetics & $\begin{array}{c}\text { More Important } \\
\text { Criteria }\end{array}$ & $\begin{array}{c}\text { Intensity of } \\
\text { Importance }\end{array}$ \\
\hline Cost & Cost & 7 \\
\hline Cost & Efficiency & Cost & 4 \\
\hline Cost & Resale Value & Cost & 5 \\
\hline Aesthetics & Efficiency & Efficiency & 7 \\
\hline Aesthetics & Resale Value & Resale Value & 3 \\
\hline Efficiency & Resale Value & Efficiency & 3 \\
\hline
\end{tabular}

Using the software tool, the manufacturer indicates the preferences above between the criteria. However, remember that one of our criteria - solar cell efficiency -- has two subcriteria. Each of these sub-criteria need to be ranked in a way that does not also violate the consistency ratios. 
Because cost, aesthetics and resale value do not have sub-criteria, we can pass over them in the analysis and proceed onto efficiency, which has two sub-criteria - thermodynamic efficiency and quantum efficiency (see Table D.3).

Table D. 3: Example of AHP Comparison of Sub-Criteria for Solar Panels

\begin{tabular}{|c|c|c|c|}
\hline & & $\begin{array}{c}\text { Most Important } \\
\text { Criteria }\end{array}$ & $\begin{array}{c}\text { Intensity of } \\
\text { Importance }\end{array}$ \\
\hline $\begin{array}{c}\text { Thermodynamic } \\
\text { Efficiency }\end{array}$ & $\begin{array}{c}\text { Quantum } \\
\text { Efficiency }\end{array}$ & $\begin{array}{c}\text { Thermodynamic } \\
\text { Efficiency }\end{array}$ & 5 \\
\hline
\end{tabular}

We can now calculate the geometric means and weights for the cost sub-criteria (see Table D.4). Unlike the traditional arithmetic mean, which is calculated by summing the data points and then dividing by the number of observations, the geometric mean is calculated by taking the product of all the observations in the data set and then taking the $n t h$ root of that product where $n$ is the number of observations in the data. For example, if we have ten observations and want to take the geometric mean, we multiply the ten observations and then take the $10^{\text {th }}$ root of that resulting product.

Table D. 4: AHP Example of Geometric Mean, Weight, and Consistency Measure for Solar Panel Sub-Criteria

\begin{tabular}{|c|c|c|c|}
\hline & Geometric Mean & Weight & $\begin{array}{c}\text { Consistency } \\
\text { Measure }\end{array}$ \\
\hline $\begin{array}{c}\text { Thermodynamic } \\
\text { Efficiency }\end{array}$ & 2.24 & 0.83 & 2 \\
\hline $\begin{array}{c}\text { Quantum Efficiency } \\
\text { Total Geometric } \\
\text { Mean }\end{array}$ & 0.45 & 0.17 & 2 \\
\hline
\end{tabular}

Now that we have calculated the sub-criteria geometric means, while maintaining the consistency ratios, we can calculate the criteria geometric means. Remember that our four criteria have been ranked against each other and can be depicted, in relation to each other, by the following table.

Table D. 5: Example of AHP Pairwise Comparison Matrix for Solar Panels

\begin{tabular}{|c|c|c|c|c|}
\hline & Cost & Aesthetics & Efficiency & Resale Value \\
\hline Cost & 1 & 7 & 4 & 5 \\
\hline Aesthetics & 0.14 & 1 & 0.14 & 0.33 \\
\hline Efficiency & 0.25 & 7 & 1 & 3 \\
\hline Resale Value & 0.2 & 3 & 0.33 & 1 \\
\hline
\end{tabular}

We can now calculate the geometric means and weights for the criteria (see Table D.6). 
Table D. 6: Example of Geometric Mean, Weight, and Consistency Measure for Solar Panels

\begin{tabular}{|c|c|c|c|}
\hline & Geometric Mean & Weight & $\begin{array}{c}\text { Consistency } \\
\text { Measure }\end{array}$ \\
\hline Cost & 3.44 & 0.58 & 4.32 \\
\hline Aesthetics & 0.29 & 0.05 & 4.24 \\
\hline Efficiency & 1.51 & 0.26 & 4.22 \\
\hline Resale Value & 0.67 & 0.11 & 4.07 \\
\hline
\end{tabular}

The results, with both criteria and sub-criteria, can be summarized here (see Table D.7):

Table D. 7: Example of AHP Weighting for Solar Panels

\begin{tabular}{|c|c|c|c|c|}
\hline Criteria & $\begin{array}{c}\text { Criteria } \\
\text { Weight }\end{array}$ & Sub-Criteria & $\begin{array}{c}\text { Sub-Criteria } \\
\text { Weight }\end{array}$ & $\begin{array}{c}\text { Global } \\
\text { Priorities }\end{array}$ \\
\hline Cost & 0.58 & & & $58.2 \%$ \\
\hline Aesthetics & 0.05 & & & $4.9 \%$ \\
\hline Efficiency & 0.26 & $\begin{array}{c}\text { Thermodynamic } \\
\text { Efficiency }\end{array}$ & 0.83 & $21.3 \%$ \\
\hline Efficiency & 0.26 & $\begin{array}{c}\text { Quantum } \\
\text { Efficiency }\end{array}$ & 0.17 & $4.3 \%$ \\
\hline Resale Value & 0.11 & & & $11.3 \%$ \\
\hline
\end{tabular}

In this hypothetical example, we now know that the manufacturers rank cost most importantly, followed by efficiency, followed by resale value, with aesthetics in last place. The weights are determined by the decision-maker's preferences and reveal the relative magnitude of importance for each criteria (i.e., cost, aesthetics, efficiency, and resale value); thus, the weights can then be used to create a single score that can be utilized to compare each option (not shown), such as choosing among solar panels. With these preferences quantified in this manner, the decision-maker can choose the option that AHP points her towards and show parties outside the decision-making process just how her decisions were made in a rigorous manner. 


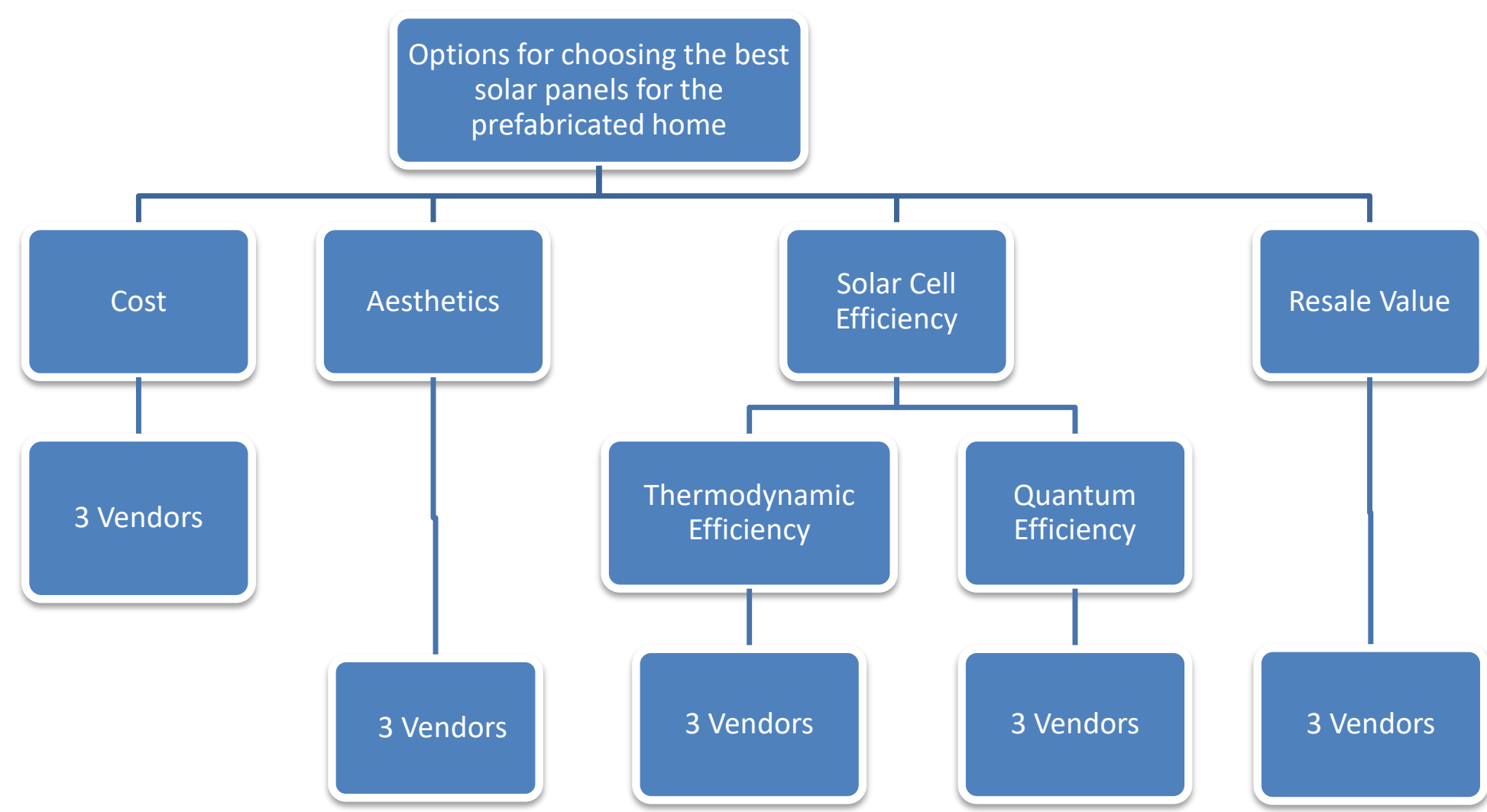

Figure D. 1: Illustration of AHP Criteria and Sub-Criteria 